\title{
NUCLEAR MASS INVENTORY, PHOTON DOSE RATE AND THERMAL DECAY HEAT OF SPENT RESEARCH REACTOR FUEL ASSEMBLIES (Rev. 2)
}

\author{
R. B. Pond and J. E. Matos \\ RERTR Program \\ Argonne National Laboratory \\ Argonne, IL 60439-4841 USA
}

May 2000

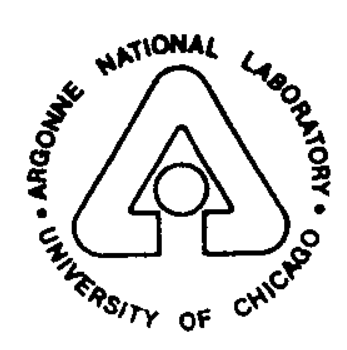

ARGONNE NATIONAL LABORATORY, ARGONNE, ILLINOIS

Operated by The University of Chicago for the United States Department of Energy under Contract No. W-31-109-Eng-38. 
Argonne National Laboratory, with facilities in the states of Illinois and Idaho, is owned by the United States government, and operated by The University of Chicago under the provisions of a contract with the Department of Energy.

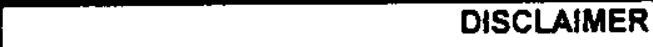

This report was prepared as an account of work sponsored by an agency of the United States Government. Neither the United States Government nor any agency thereof, nor any of their employees, makes any warranty, expressed or implied, or assumes any legal liability or responsibility for the accuracy, completeness, or usefulness of any information, apparatus, product, or process disclosed, or represents that its use would not infringe privately owned rights. Reference herein to any specific commercial product, process, or service by trade name, trademark, manufacturer, or othenwise, does not necessarily constitute or imply its endorsement, recommendation, or favoring by the United States Govemment or any agency thereof. The views and opinions of authors expressed herein do not necessarily state or refiect those of the United States Government or any agency thereof.

Available from the

Reduced Enrichment for Research and Test Reactor (RERTR) Program

Argonne National Laboratory

9700 South Cass Avenue

Argonne, IL 60439-4841 USA 


\title{
NUCLEAR MASS INVENTORY, PHOTON DOSE RATE AND THERMAL DECAY HEAT OF SPENT RESEARCH REACTOR FUEL ASSEMBLIES (Rev. 2)
}

\author{
R. B. Pond and J. E. Matos \\ RERTR Program \\ Argonne National Laboratory \\ Argonne, IL 60439-4841 USA
}

May 2000

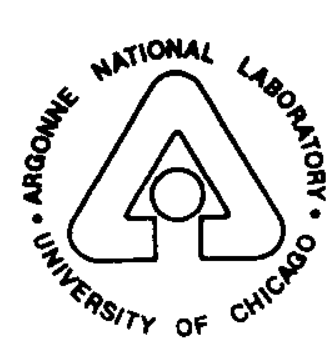

ARGONNE NATIONAL LABORATORY, ARGONNE, ILLINOIS

Operated by The University of Chicago for the United States Department of Energy under Contract No. W-31-109-Eng-38. 


\section{NUCLEAR MASS INVENTORY, PHOTON DOSE RATE AND THERMAL DECAY HEAT OF SPENT RESEARCH REACTOR FUEL ASSEMBLIES (Rev. 2)}

\section{TABLE OF CONTENTS}

\section{$\underline{\text { Page }}$}

Revison-1 Record

Revison-2 Record

Summary

Introduction

Nuclear Mass Inventory

Photon Dose Rate

Thermal Decay Heat

Conclusions

References

Appendix A: MTR Model Mass Inventory Sensitivity

Appendix B: U-234 And U-236 Mass Inventory Sensitivity

Appendix C: Mass Inventory Estimate: ORIGEN Vs. WIMS

Appendix D: Example Calculation: Nuclear Mass Inventory, Photon Dose Rate, Thermal Decay Heat And Fission Product Decay Rate 


\section{NUCLEAR MASS INVENTORY, PHOTON DOSE RATE AND THERMAL DECAY HEAT OF SPENT RESEARCH REACTOR FUEL ASSEMBLIES (Rev. 1)}

\section{REVISION-1 RECORD}

ANL/RERTR/TM-26 (original issue May 1996) has been revised as follows:

Table 5 has been revised to increase the burnup range of TRIGA single-rod fuel from 35 to $60 \%{ }^{235} \mathrm{U}$ burnup.

Alternative thermal decay heat expressions have been included which are expected to give results close to actual heat loads of spent fuel. The previous thermal decay heat expression is expected to overestimate an actual heat load by about a factor of two. An analysis of the parameter constants used in the previous expression would suggest an uncertainty in calculated heat loads of the order of $10 \%$. A decay heat comparison has been made for a typical fuel assembly using the ORIGEN code and the decay heat expressions.

Appendix $\mathrm{C}$ has been added which compares mass inventory estimates using the isotope generation and depletion code, ORIGEN and the cross section generation code, WIMS. Both codes solve material transmutation equations to determine material number densities. WIMS, however, solves the equations as a function of material burnup, while ORIGEN does not have a similar capability.

Appendix D has been added to illustrate an example calculation of the nuclear mass inventory, the photon dose rate, and the thermal decay heat for an assumed, spent MTR-type fuel assembly. All fuel assembly parameters necessary for the calculations are described. 


\section{NUCLEAR MASS INVENTORY, PHOTON DOSE RATE AND THERMAL DECAY HEAT OF SPENT RESEARCH REACTOR FUEL ASSEMBLIES (Rev. 2)}

\section{REVISION-2 RECORD}

ANL/RERTR/M-26 (rev. 1 issue December 1996) has been revised as follows:

Table 2 has been extended to include the mass inventory of 500, 600, 700 and 800 gram U-235 MTR-type 93\% enriched fuel.

The section entitled 'Thermal Decay Heat' has been expanded to include a correlation of the fission product decay rate and the thermal decay heat in spent research reactor fuel. The correlation indicates that the ratio of the radioactivity in curies to the heat load in watts is 200 or more depending upon the spent fuel irradiation history and the fission product decay time.

The Appendix D example calculation of mass inventory, photon dose rate and thermal decay heat of a typical spent fuel assembly now also includes a calculation of the fission product decay rate. 


\title{
NUCLEAR MASS INVENTORY, PHOTON DOSE RATE AND THERMAL DECAY HEAT \\ OF SPENT RESEARCH REACTOR FUEL ASSEMBLIES (Rev. 2)
}

\author{
R. B. Pond and J. E. Matos \\ Argonne National Laboratory \\ Argonne, IL
}

\section{SUMMARY}

This document has been prepared to assist research reactor operators possessing spent fuel containing enriched uranium of United States origin to prepare part of the documentation necessary to ship this fuel to the United States. Data are included on the nuclear mass inventory, photon dose rate, thermal decay heat, and fission product decay rate of spent research reactor fuel assemblies.

Isotopic masses of $\mathrm{U}, \mathrm{Np}, \mathrm{Pu}$ and $\mathrm{Am}$ that are present in spent research reactor fuel are estimated for MTR, TRIGA and DIDO fuel assembly types. The isotopic masses of each fuel assembly type are given as functions of U-235 burnup in the spent fuel, and of initial U-235 enrichment and U-235 mass in the fuel assembly.

Photon dose rates of spent MTR, TRIGA and DIDO-type fuel assemblies are estimated for fuel assemblies with up to $80 \%$ U-235 burnup and specific power densities between 0.089 and $2.857 \mathrm{MW} / \mathrm{kg}^{235} \mathrm{U}$, and for fission product decay times of up to 20 years.

Thermal decay heat load and fission product radioactivity is estimated for spent fuel based upon the fuel assembly irradiation history (average assembly power vs. elapsed time) and the spent fuel cooling time.

\section{INTRODUCTION}

As part of the Department of Energy's spent nuclear fuel acceptance criteria, the mass of uranium and transuranic elements in spent research reactor fuel must be specified. These data are, however, not always known or readily determined. It is the purpose of this report to provide estimates of these data for some of the more common research-reactor fuel-assembly types. The specific types considered here are MTR, TRIGA and DIDO fuel assemblies. 
The degree of physical protection given to spent-fuel assemblies is largely dependent upon the photon dose rate of the spent fuel material. These data also, are not always known or readily determined. Because of a self-protecting dose rate level of radiation (dose rate greater than $100 \mathrm{rem} / \mathrm{h}$ at $1 \mathrm{~m}$ in air), it is important to know the dose rate of spent fuel assemblies at all time. Estimates of the photon dose rate for spent MTR, TRIGA and DIDO-type fuel assemblies are given in this report.

For safe spent fuel assembly containment, the thermal heat load generated by the decay of fission products in spent fuel material is an important consideration. This heat load can be estimated by a simple analytical expression that is given in this report.

\section{NUCLEAR MASS INVENTORY}

The mass inventory of the heavy metals in research reactor fuels has been calculated using the WIMS code ${ }^{1}$ for unit-cell models of MTR, TRIGA and DIDO fuel assembly types. Models of each fuel assembly type were neutronically burned for a length of time corresponding to typical fuel-cycle lengths and U-235 burnup ${ }^{2}$. Table 1 summarizes the fuel assembly models for which mass inventory calculations were made.

Table 1. Fuel Assembly Models

\begin{tabular}{|c|c|c|c|}
\hline Assembly Type & U-235 Burnup, \% & U-235 Enrichment, \% & U-235 Mass, 9 \\
\hline MTR & $5,10,20,30,40,50,60,70,80$ & 93 & 100200300400500 \\
(19 fuel plates) & & 600700800 \\
& & 45 & 200300400 \\
& & 19.75 & 100200300400500 \\
\hline TRIGA & $5,10,15,20,25,30,35,40,45$, & $70(8.5 \mathrm{w} \% \mathrm{U})$ & 133 \\
(single rod) & $50,55,60$ & $20(20 \mathrm{w} \% \mathrm{U})$ & 98 \\
& & $20(12 \mathrm{w} \% \mathrm{U})$ & 54 \\
& & $20(8.5 \mathrm{w} \% \mathrm{U})$ & 38 \\
\hline TRIGA & $10,20,30,40,50,60$ & $93.1(10 \mathrm{wt} \% \mathrm{U})$ & 41.4 \\
(25 rod cluster) & & $19.7(45 \mathrm{w} \% \mathrm{U})$ & 53.6 \\
\hline DIDO & $10,20,30,40,50,60$ & 93 & 150 \\
(4 fuel tubes) & & 80 & 150 \\
& & 60 & 150 \\
& & 20 & 200 \\
\hline
\end{tabular}

Mass inventory calculations for MTR models were made for assemblies with up to $80 \%$ U-235 burnup, for 93,45 and $19.75 \%$ U-235 enrichments. The specific MTR model was for a 19-fuel plate assembly. (Supplemental mass inventory calculations, shown in Appendix A, indicate that the MTR model in not a strong function of the number of fuel plates or the specific fuel-clad-coolant geometry.)

Similar calculations were made for two TRIGA assembly types - a single rod model and a 25 -rod cluster model. The maximum U-235 burnup in these models was $60 \%$. There were four fuel types for the single rod model and two fuel types for the cluster model. 
For DIDO fuel assembly types, mass inventory calculations were made for a 4fuel tube model with up to $60 \%$ U-235 burnup, and for four fuel enrichments and assembly masses.

The results of the mass inventory calculations are shown in the following tables:

Table 2 - MTR Fuel 93\% Enrichment, Page 13

Table 3-MTR Fuel 45\% Enrichment, Page 17

Table 4 - MTR Fuel $19.75 \%$ Enrichment, Page 19

Table 5 - TRIGA Fuel Single-Rod Model, Page 22

Table 6 - TRIGA Fuel 25-Rod Cluster Model, Page 24

Table 7 - DIDO Fuel, Page 25

The tables show the isotopic masses of $\mathrm{U}, \mathrm{Np}, \mathrm{Pu}$ and $\mathrm{Am}$ that are present in spent fuel as functions of the fuel assembly U-235 burnup and initial U-235 mass. As will be noted in the tables for most fuel assembly types, the uranium fuel compositions have excluded initial enrichments of U-234 and U-236. In order to account for initial enrichments of U234 and/or U-236 in the tables, initial U-234 and U-236 masses can be simply added to the spent fuel mass inventory. (See Appendix B for an assessment of the effect of initial enrichments of U-234 and U-236 upon the overall mass inventory of U, Np, Pu and Am in spent fuel.) Within the uncertainty of the calculations, the results in Tables 2-7 can be used to estimate the spent fuel mass inventory in most MTR, TRIGA and DIDO fuel assembly types. (See Appendix $\mathrm{C}$ for a comparison of calculational techniques.)

The mass inventories given in Tables 2-7 are at the time of reactor discharge and therefore do not account for decay of Pu-241 to Am-241 for times after discharge. When necessary to estimate mass inventories after discharge, the Pu-241 mass is decreased and the Am-241 mass is increased by an amount $\Delta M=M_{0} \cdot\left(1-e^{-\lambda l}\right)$ where $M_{0}$ is the Pu241 mass at discharge, $\lambda=132 \cdot 10^{-4} \mathrm{~d}^{-1}(\mathrm{Pu}-241$ half-life, $14.4 \mathrm{y})$, and $t$ is the time in days after discharge. No mass inventories are given for U-239 (half-life, $23.5 \mathrm{~m}$ ) and Np239 (half-life, $2.355 \mathrm{~d}$ ) as they are assumed to decay instantaneously to Pu-239.

\section{PHOTON DOSE RATE}

Calculated dose rates for MTR-type fuel assemblies are shown in Table 8. These dose rates are from Ref. 3 and are for fuel assemblies with up to $80 \%$ U-235 burnup, specific power densities between 0.089 and $2.857 \mathrm{MW} / \mathrm{kg}^{235} \mathrm{U}$, and fission product decay times of up to 20 years.

The data in Table 8 are photon dose rates in air that are averaged over a $60-\mathrm{cm}$ long cylindrical surface, located at a radius of $1 \mathrm{~m}$ from the fuel assembly axial center line. For MTR-type fuel assemblies, these average dose rates are independent of the assembly rotational orientation and the number of fuel plates in the assembly. These data also can be interpolated for specific decay time, burnup and assembly power density. In all cases, the dose rates must be multiplied by the mass of U-235 burned in the fuel assembly to estimate the fuel assembly dose rate. The mass of $U-235$ burned per fuel 
assembly that is necessary for an unshielded, $100-\mathrm{rem} / \mathrm{h}$ self-protecting dose rate at $1 \mathrm{~m}$, is shown in Fig. 1.

Additional analyses have shown that the photon dose rates of MTR, TRIGA and DIDO-type fuel assemblies are similar, given the same fuel assembly characteristics of U235 burnup, fission product decay time, and specific fuel assembly power density. The average dose rates at $1 \mathrm{~m}$ in air for TRIGA (25-rod) and DIDO (4-tube) fuel assemblies are respectively, 1.04 and 1.05 times the dose rates given in Table 8 for MTR fuel assemblies. The dose rates of all three fuel assembly types are for fuel assembly models (nominally $8 \mathrm{~cm}$ by $8 \mathrm{~cm}$ by $60 \mathrm{~cm}$ ) containing spent fuel in the form of either rods (TRIGA fuel), annuli (DIDO fuel) or plates (MTR fuel). The small differences in the dose rates are due to the different shielding effects of the fuel elements in the fuel assemblies.

Table 8. Photon Dose Rates At $1 \mathrm{M}$ In Air, rem/h per $\mathrm{g}^{238} \mathrm{U}$ burned

\begin{tabular}{|c|c|c|c|c|c|c|c|}
\hline \multirow{2}{*}{$\begin{array}{l}\text { Decay } \\
\text { Time,y }\end{array}$} & \multirow{2}{*}{$\begin{array}{c}\text { Bumup, } \\
\%\end{array}$} & \multicolumn{6}{|c|}{ Assembly Power Density, MW/ $\mathrm{kg}^{255} \mathrm{U}$} \\
\hline & & 2.857 & 1.429 & 0.714 & 0.357 & 0.179 & 0.089 \\
\hline $\begin{array}{l}2 \\
3 \\
4\end{array}$ & $1 \%$ & $\begin{array}{l}1.84+0 \\
1.13+0 \\
9.01-1\end{array}$ & $\begin{array}{l}1.84+0 \\
1.13+0 \\
9.01-1\end{array}$ & $\begin{array}{l}1.83+0 \\
1.13+0 \\
9.01-1\end{array}$ & $\begin{array}{l}1.80+0 \\
1.13+0 \\
9.01-1\end{array}$ & $\begin{array}{l}1.77+0 \\
1.11+0 \\
9.01-1\end{array}$ & $\begin{array}{l}1.70+0 \\
1.11+0 \\
8.92-1\end{array}$ \\
\hline $\begin{array}{l}2 \\
3 \\
4\end{array}$ & $10 \%$ & $\begin{array}{l}1.89+0 \\
1.19+0 \\
9.52-1\end{array}$ & $\begin{array}{l}1.87+0 \\
1.20+0 \\
9.61-1\end{array}$ & $\begin{array}{l}1.80+0 \\
1.20+0 \\
9.61-1\end{array}$ & $\begin{array}{l}1.64+0 \\
1.16+0 \\
9.44-1\end{array}$ & $\begin{array}{l}1.50+0 \\
1.09+0 \\
9.10-1\end{array}$ & $\begin{array}{l}1.28+0 \\
9.95-1 \\
8.59-1\end{array}$ \\
\hline $\begin{array}{c}2 \\
3 \\
4 \\
5 \\
10 \\
15 \\
20\end{array}$ & $20 \%$ & $\begin{array}{l}2.01+0 \\
1.31+0 \\
1.04+0 \\
8.97-1 \\
6.67-1 \\
5.78-1 \\
5.10-1\end{array}$ & $\begin{array}{l}1.98+0 \\
1.32+0 \\
1.05+0 \\
9.10-1 \\
6.67-1 \\
5.78-1 \\
5.10-1\end{array}$ & $\begin{array}{l}1.86+0 \\
1.28+0 \\
1.04+0 \\
9.05-1 \\
6.67-1 \\
5.74-1 \\
5.10-1\end{array}$ & $\begin{array}{l}1.66+0 \\
1.21+0 \\
9.99-1 \\
8.80-1 \\
6.59-1 \\
5.70-1 \\
5.06-1\end{array}$ & $\begin{array}{l}1.42+0 \\
1.11+0 \\
9.44-1 \\
8.46-1 \\
6.50-1 \\
5.61-1 \\
4.97-1\end{array}$ & $\begin{array}{l}1.19+0 \\
9.78-1 \\
8.63-1 \\
7.95-1 \\
6.25-1 \\
5.44-1 \\
4.85-1\end{array}$ \\
\hline $\begin{array}{c}2 \\
3 \\
4 \\
5 \\
10 \\
15 \\
20\end{array}$ & $40 \%$ & $\begin{array}{l}2.40+0 \\
1.62+0 \\
1.27+0 \\
1.07+0 \\
7.03-1 \\
5.87-1 \\
5.14-1\end{array}$ & $\begin{array}{l}2.30+0 \\
1.60+0 \\
1.27+0 \\
1.07+0 \\
7.03-1 \\
5.84-1 \\
5.12-1\end{array}$ & $\begin{array}{l}2.09+0 \\
1.53+0 \\
1.22+0 \\
1.04+0 \\
6.95-1 \\
5.80-1 \\
5.08-1\end{array}$ & $\begin{array}{l}1.82+0 \\
1.39+0 \\
1.14+0 \\
9.90-1 \\
6.80-1 \\
5.70-1 \\
5.02-1 \\
\end{array}$ & $\begin{array}{l}1.52+0 \\
1.22+0 \\
1.03+0 \\
9.20-1 \\
6.55-1 \\
5.53-1 \\
4.87-1 \\
\end{array}$ & $\begin{array}{l}1.21+0 \\
1.02+0 \\
8.99-1 \\
8.12-1 \\
6.10-1 \\
5.23-1 \\
4.59-1 \\
\end{array}$ \\
\hline $\begin{array}{c}2 \\
3 \\
4 \\
5 \\
10 \\
15 \\
20 \\
\end{array}$ & $60 \%$ & $\begin{array}{l}2.95+0 \\
2.05+0 \\
1.59+0 \\
1.30+0 \\
7.55-1 \\
5.96-1 \\
5.17-1\end{array}$ & $\begin{array}{l}2.79+0 \\
2.00+0 \\
1.56+0 \\
1.29+0 \\
7.51-1 \\
5.96-1 \\
5.17-1\end{array}$ & $\begin{array}{l}2.52+0 \\
1.87+0 \\
1.49+0 \\
1.24+0 \\
7.37-1 \\
5.88-1 \\
5.13-1 \\
\end{array}$ & $\begin{array}{l}2.15+0 \\
1.66+0 \\
1.35+0 \\
1.15+0 \\
7.07-1 \\
5.72-1 \\
4.99-1 \\
\end{array}$ & $\begin{array}{l}1.74+0 \\
1.40+0 \\
1.17+0 \\
1.02+0 \\
6.70-1 \\
5.50-1 \\
4.76-1 \\
\end{array}$ & $\begin{array}{l}1.34+0 \\
1.12+0 \\
9.63-1 \\
8.54-1 \\
6.02-1 \\
5.04-1 \\
4.39-1 \\
\end{array}$ \\
\hline $\begin{array}{c}2 \\
3 \\
4 \\
5 \\
10 \\
15 \\
20\end{array}$ & $80 \%$ & $\begin{array}{l}3.85+0 \\
2.73+0 \\
2.08+0 \\
1.66+0 \\
8.28-1 \\
6.18-1 \\
5.27-1\end{array}$ & $\begin{array}{l}-3.62+0 \\
2.64+0 \\
2.03+0 \\
1.63+0 \\
8.21-1 \\
6.15-1 \\
5.20-1\end{array}$ & $\begin{array}{l}3.26+0 \\
2.43+0 \\
1.90+0 \\
1.54+0 \\
8.00-1 \\
6.05-1 \\
5.13-1\end{array}$ & $\begin{array}{l}2.76+0 \\
2.11+0 \\
1.69+0 \\
1.39+0 \\
7.59-1 \\
5.82-1 \\
4.97-1 \\
\end{array}$ & $\begin{array}{l}2.21+0 \\
1.74+0 \\
1.41+0 \\
1.19+0 \\
6.97-1 \\
5.44-1 \\
4.66-1\end{array}$ & $\begin{array}{l}1.64+0 \\
1.33+0 \\
1.12+0 \\
9.57-1 \\
6.04-1 \\
4.87-1 \\
4.20-1\end{array}$ \\
\hline
\end{tabular}



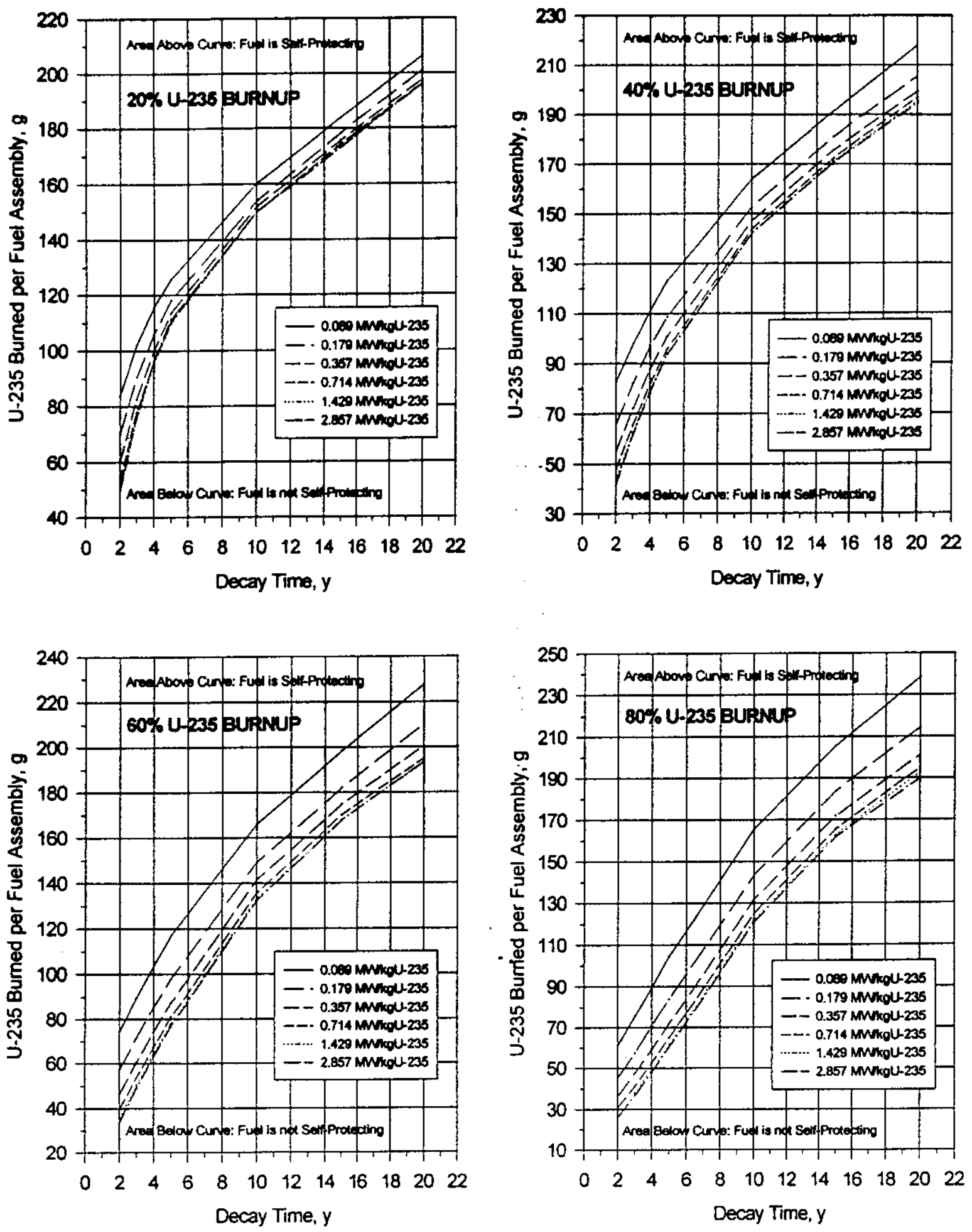

Figure 1. Mass of Burned ${ }^{238} \mathrm{U}$ per Fuel Assembly Necessary for an Unshielded $100 \mathrm{rem} / \mathrm{h}$ Dose Rate at $1 \mathrm{~m}$ for Fuel Assemblies with 20, 40,60 and $80 \%{ }^{235} \mathrm{U}$ Burnup and Power Densities from 0.089 to $2.857 \mathrm{MW} / \mathrm{kg}^{235} \mathrm{U}$ 


\section{THERMAL DECAY HEAT}

The textbook development of calculating the thermal decay heat of reactor fuel is based upon integrating empirical emission rates of the beta and gamma radiation from fission products. These results are, however, generally useful only for fission product decay times of the order of a few days. For longer decay times, this heat load estimate is very conservative.

Other analytical expressions have been developed to fit experimental decay heat data for longer decay times. For purposes of determining the heat load of spent fuel which can have cooling times of the order of several hundred days or even years, these latter expressions should be used to calculate the heat load of spent reactor fuel. These analytical expressions also agree very well with ORIGEN decay heat calculations.

\section{Integrated Beta And Gamma Emission Rates}

The heat load from decaying fission products in a fuel assembly is proportional to empirical emission rates of beta and gamma radiation. The rates ${ }^{4}$ per U-235 fission, and as a function of decay time $t_{d}$ in days, are

$$
\begin{aligned}
& \beta\left(t_{d}\right)=1.50 \cdot 10^{-6} \cdot t_{d}-1.2 \mathrm{MeV} / \mathrm{s}-\mathrm{f} \\
& \gamma\left(t_{d}\right)=1.67 \cdot 10^{-6} \cdot t_{d}^{-1.2} \mathrm{MeV} / \mathrm{s}-\mathrm{f}
\end{aligned}
$$

These energy rates are roughly equal for $0.4 \mathrm{MeV}$ mean energy beta particles and 0.7 $\mathrm{MeV}$ mean energy gamma rays.

For a fuel assembly irradiated continuously for $t_{i}$ days at a constant fuel assembly power $(P)$, the heat $(H)$ load power per assembly, $t_{d}$ days after irradiation is

$$
H=6.85 \cdot 10^{-3} \cdot P \cdot\left(t_{d}{ }^{-0.2}-\left(t_{i}+t_{d}\right)^{-0.2}\right) \text { Watts }
$$

This expression for the heat load is the integral ${ }^{5}$ of the above energy rates over the irradiation time, assuming $200 \mathrm{MeV}$ per U-235 fission, and for the fuel assembly power in watts. For a low duty-factor fuel-assembly irradiation, the power and irradiation time are replaced by an average power and an elapsed time. With $\bar{P} \cdot t_{e}=\sum\left(P \cdot t_{i}\right)$ over all irradiation segments, the heat $(H)$ load power per assembly is

$$
H \cong 6.85 \cdot 10^{-3} \cdot \bar{P} \cdot\left(t_{d}{ }^{-0.2}-\left(t_{e}+t_{d}\right)^{-0.2}\right) \text { Watts }
$$

where $\bar{P}$ is the average fuel assembly power in watts and $t_{e}$ is the elapsed time in days from the initial through the final irradiation segment. 
A convenient estimate for the average power $(\bar{P})$ is

$$
\bar{P}=\left(G / t_{e}\right) / 1.25 \cdot 10^{-6} \text { Watts }
$$

where $G$ is the mass of $U-235$ burned in the fuel assembly in grams, and the constant is $\mathrm{g}^{235} \mathrm{U}$ burned per Watt-day.

An estimate of the fuel assembly radioactivity can be made based upon the above empirical beta particle emission rate $1.50 \cdot 10^{-6} \cdot t_{d}^{-1.2} \mathrm{MeV} / \mathrm{s}-\mathrm{f}$ and the $0.4 \mathrm{MeV}$ per $\beta$ particle. The emission rate would be $3.75 \cdot 10^{-6} \cdot t_{d}^{-1.2} \beta / \mathrm{s}$-f or $1.01 \cdot 10^{-16} \cdot t_{d}^{-1.2}$ Curies/f. The radioactivity integral $(A)$, similar to the decay heat integral (Eq. -1 ), is

$$
A=1.37 \cdot P \cdot\left(t_{d}^{-0.2}-\left(t_{i}+t_{d}\right)^{-0.2}\right) \text { Curies }
$$

The ratio of the radioactivity $(A)$ in curies to the decay heat $(H)$ in watts is about 200 .

A similar heat load expression to Eq. -1, given by Etherington (Ref. 6) and attributed to Way and Wigner (Ref. 7 and 8), is

$$
H=6.22 \cdot 10^{-2} \cdot P \cdot\left(t_{d}{ }^{-0.2}-\left(t_{i}+t_{d}\right)^{-0.2}\right) \text { Watts }
$$

with all times in seconds. With all times in days, this heat load expression is

$$
H=6.40 \cdot 10^{-3} \cdot P \cdot\left(t_{d}{ }^{-0.2}-\left(t_{i}+t_{d}\right)^{-0.2}\right) \text { Watts }
$$

(Note: the Etherington reference to Way and Wigner appears to be incorrect. Reference 7 is Vol. 73 (not Vol. 70) ${ }^{6}$ of Phys. Rev.; Ref. 8 may be the intended reference. However neither Ref. 7 or 8 appears to have the formula attributed to Way and Wigner. Reference 8 however, lists the same (but switched), $\beta$ and $\gamma$ emission rates used to develop Eq. -1 , which results in a heat load expression constant of $6.85 \cdot 10^{-3}$.) This and other similar heat load expressions, which differ only by the constant, can be readily found in the literature (e.g., Ref. $5,5.7 \cdot 10^{-2}$ for times in seconds and $5.9 \cdot 10^{-3}$ for times in days).

Fuel assembly decay heat loads calculated with these expressions are expected to be conservative, and within a factor of two or less of measured heat loads. This same conservative heat load estimate also has been found to be true for heat load calculations made with the ORIGEN code ${ }^{9}$. The thermal heat load of a fuel assembly is independent of the fuel assembly type. 
The constants used in the above equations are based upon empirical data and therefore, are not necessarily exact; it is not uncommon to find several percent variations in a recommended value. The constants considered here and their range are:

1. The beta plus gamma fission product energy rate per fission, $2.7-3.2 \cdot 10^{-6} \mathrm{MeV} / \mathrm{s}-\mathrm{f}$

2. The total energy release per fission, $190-200 \mathrm{MeV} / \mathrm{f}$; and

3. The mass of ${ }^{235} \mathrm{U}$ burned per megawatt-day, $1.2-1.3 \mathrm{~g}^{235} \mathrm{U} / \mathrm{MWd}$.

Depending upon the specific values of the constants that are chosen, the calculated heat load can vary by several percent. In any case, the thermal decay heat (Eq.-1) is expected to be over predictive.

\section{Decay Heat Curves}

An analytical expression given by El-Wakil (Ref. 10), which correlate with the decay heat curves of Ref. 11, estimate heat loads about one-half the heat loads calculated above. This heat load expression is

$$
H=4.95 \cdot 10^{-3} \cdot P \cdot t_{d}{ }^{-0.06} \cdot\left(t_{d}{ }^{-0.2}-\left(t_{i}+t_{d}\right)^{-0.2}\right) \text { Watts }
$$

where all symbols, etc. have the same meaning as above and the times are in days.

The ratio of Eq. -2 to Eq. -1 is

$$
4.95 \cdot t_{d}{ }^{-0.06} / 6.85=0.72 \cdot t_{d}-0.06
$$

For decay times $\left(t_{d}\right)$ greater than 1 year, the ratio is approximately 0.5 .

\section{Experimental Decay Heat Data}

Another analytical expression given by Untermyer and Weills (Ref. 12) has been used to fit experimental decay heat data. This heat load expression is

$$
\begin{aligned}
H= & 0.1 \cdot P \cdot\left[\left(t_{d}+10\right)^{-0.2}-\left(t_{i}+t_{d}+10\right)^{-0.2}\right] \\
& -0.087 \cdot P \cdot\left[\left(t_{d}+2 \cdot 10^{7}\right)^{-0.2}-\left(t_{i}+t_{d}+2 \cdot 10^{7}\right)^{-0.2}\right] \text { Watts }
\end{aligned}
$$

where the irradiation $\left(t_{i}\right)$ and decay $\left(t_{d}\right)$ times are in seconds. 
A plot of the ratio $(H / P)$ for Eqs. -2 and -3 are shown in Fig. 2 as a function of decay time and for an irradiation time of 600 days. The ratio calculated with the ORIGEN code is also shown for comparison.

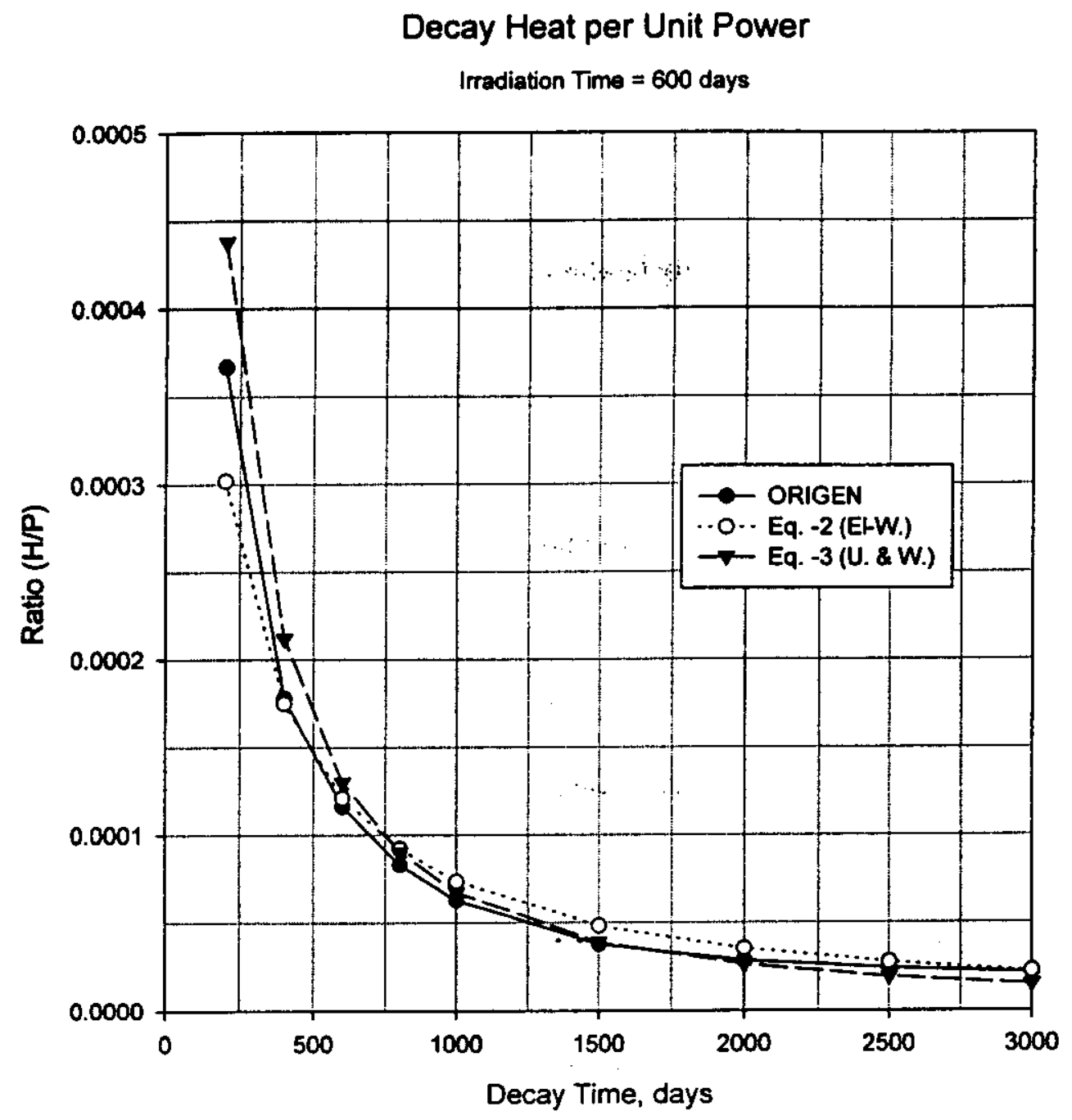

Figure 2. Comparison of Decay Heat Equations-2 and -3 with ORIGEN

These data clearly show the relative decay heat estimated by the decay heat expressions for a typical irradiation time. The ORIGEN ratio is in good agreement with both Eqs. -2 and -3 . 
Correlations of the fission product radioactivity and the heat loads given by Eqs. 2 and -3 have been developed using the fission product disintegration rates calculated with the PHDOSE program (Ref. 3). These correlations are shown in Figs. 3 and 4 as functions of the irradiation time $\left(t_{i}\right)$ in days and the decay time $\left(t_{d}\right)$ in years. The vertical axis is the ratio of the fission product radioactivity in curies to the fission product thermal decay heat in watts. Using the calculated heat load from Eqs. -2 or -3 , the decay rates can be estimated. The correlations start at a decay rate-to-decay heat ratio of about 200 and generally increase as irradiation times and decay times increase.

Depending upon the interpolation of the irradiation and/or decay times, both the Fig. 3 and Fig. 4 correlations should result in the same estimated fission product radioactivity. A comparison of fission product radioactivity calculated with the PHDOSE and ORIGEN programs shows an overall difference of about $10 \%$ with the PHDOSE results being less than the ORIGEN results. This is due primarily to fewer fission products included in PHDOSE than in ORIGEN. Neglecting, as well, a small dependence of the radioactivity as a function of burnup, the Fig. 3 and Fig. 4 fission product radioactivity's should therefore be increased by about $10 \%$.

\section{CONCLUSIONS}

Procedures have been developed to estimate the nuclear mass inventory, the photon dose rate, the thermal decay heat and the radioactivity of spent research reactor fuel assemblies. The procedures should provide reasonable estimates based upon known fuel assembly parameters. Estimates for an example spent fuel assembly are given in Appendix D.

Isotopic mass inventories of $\mathrm{U}, \mathrm{Np}, \mathrm{Pu}$ and $\mathrm{Am}$ are tabulated in Tables 2-7 for MTR, TRIGA and DIDO fuel assembly types; and photon dose rates at $1 \mathrm{~m}$ in air are shown in Table 8 for MTR-type fuel assemblies. Estimates of TRIGA and DIDO fuel assembly photon dose rates are respectively, factors of 1.04 and 1.05 times the dose rate for MTR-type fuel assemblies with similar spent fuel material characteristics. Analytical expressions (Eqs. -2 and -3 ) are given for the thermal decay heat load of spent uranium fuel; and fission product decay rates (Figs. 3 and 4 ) are given as functions of the thermal decay heat. 
Radioactivity (PHDOSE) - Heat Load (Eq. -2) Correlation

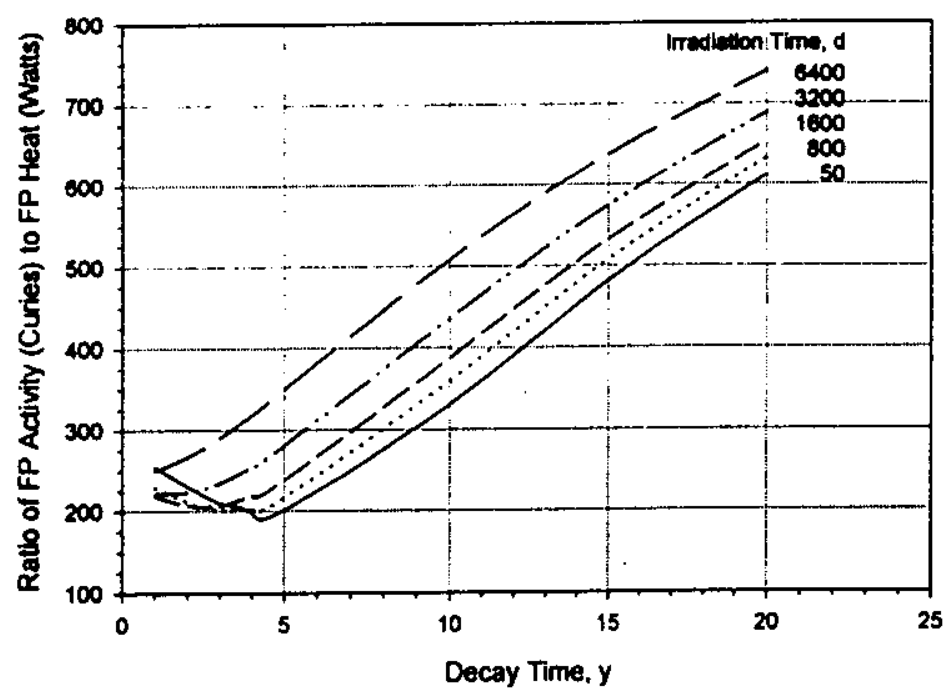

Figure 3. Radioactivity - Heat Load (Eq. -2) Fission Product Correlation

Radioactivity (PHDOSE) - Heat Load (Eq. -3) Correlation

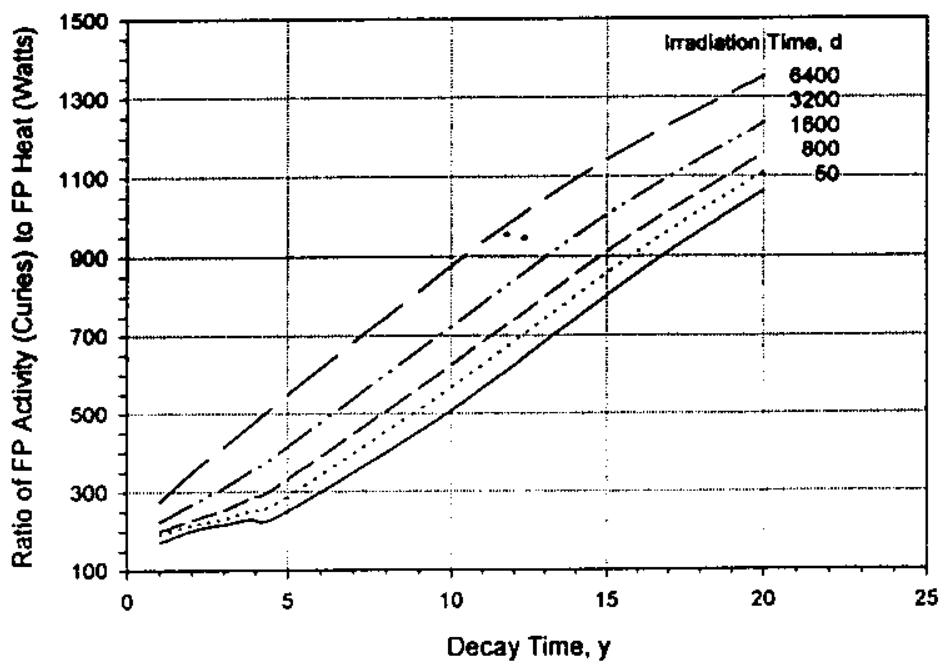

Figure 4. Radioactivity - Heat Load (Eq. -3) Fission Product Correlation 


\section{REFERENCES}

1. J. R. Deen, W. L. Woodruff and C.I. Costescu, "WIMS-D4M User Manual (Rev. 0)," ANL/RERTR/TM-23, Argonne National Laboratory, Argonne, IL (July 1995).

2. J. E. Matos, "Foreign Research Reactor Irradiated Nuclear Fuel Inventories Containing HEU And LEU Of United States Origin," ANL/RERTR/TM-22, Argonne National Laboratory, Argonne, IL (December 1994).

3. R. B. Pond and J. E. Matos, "Photon Dose Rates From Spent Fuel Assemblies With Relation To Self-Protection (Rev. 1)," ANL/RERTR/TM-25, Argonne National Laboratory, Argonne, IL (February 1996); see also, Internet site http://www.td.anl.gov/RERTR/RERTR.html.

4. A. M. Weinberg and E. P. Wigner, "The Physical Theory Of Neutron Chain Reactors," p. 133, University of Chicago Press, Chicago, IL (1958).

5. S. Glasstone, "Principles Of Nuclear Reactor Engineering," p. 118, D. Van Nostrand Company, Princeton, NJ (1955).

6. H. Etherington, Ed., "Nuclear Engineering Handbook," p. 7-15, McGraw-Hill Book Company, New York, NY (1958).

7. K. Way and E. P. Wigner, "The Rate Of Decay Of Fission Products," Phys. Rev., 73, 1318 (1948).

8. K. Way and E. P. Wigner, "Radiation From Fission Products," Phys. Rev., 70, 115 (1946).

9. M. J. Bell, "ORIGEN - The ORNL Isotope Generation And Depletion Code," ORNL-4628, Oak Ridge National Laboratory, Oak Ridge, TN (May 1973).

10. M. M. El-Wakil, "Nuclear Heat Transport," p. 94, International Textbook Company, Scranton, PA (1971).

11. "Reactor Physics Constants," ANL-5800, p. 634, Argonne National Laboratory, Argonne, IL (July 1963).

12. S. Untermyer and J. T. Weills, "Heat Generation In Irradiated Uranium," ANL-4790, Argonne National Laboratory, Argonne, IL (February 1952). 


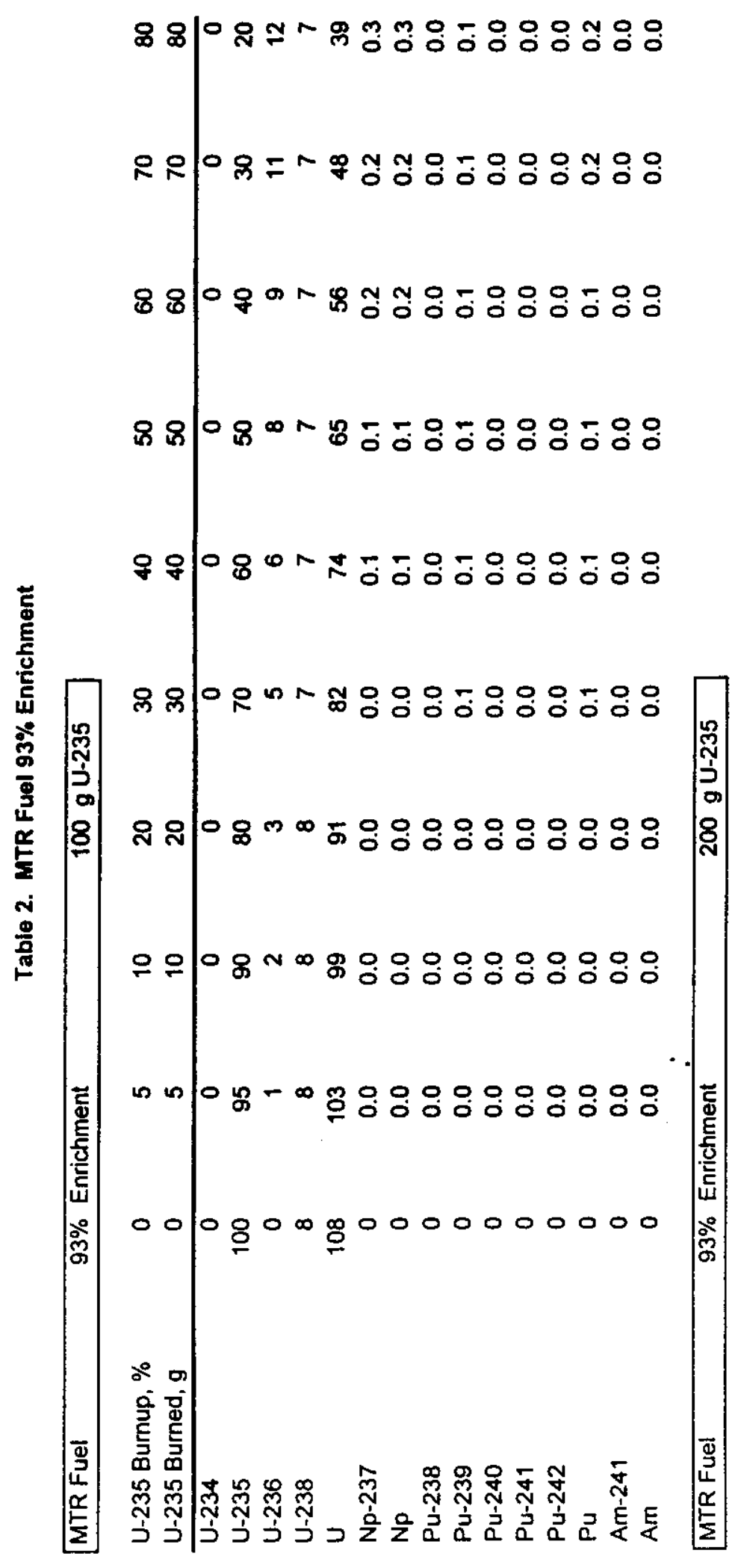

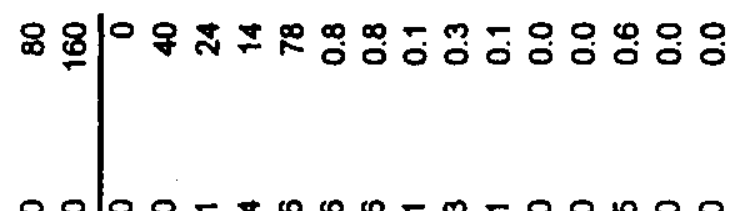

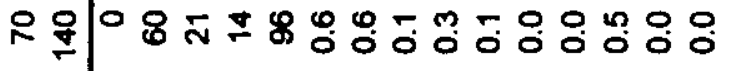

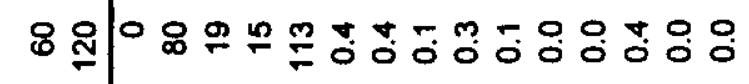

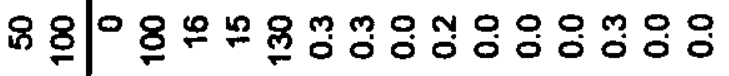

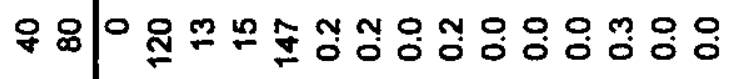

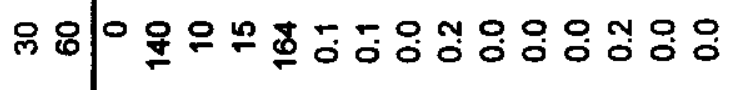

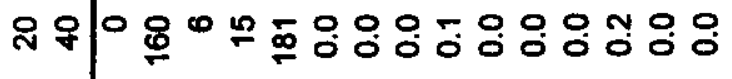

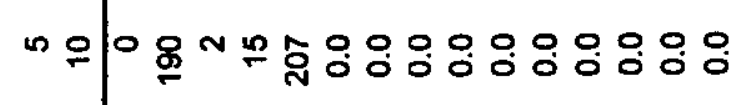

$00000 \frac{\pi}{n} 0000000000$

$\therefore$

을 월

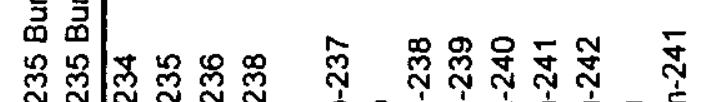

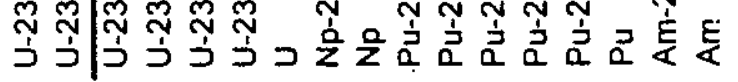




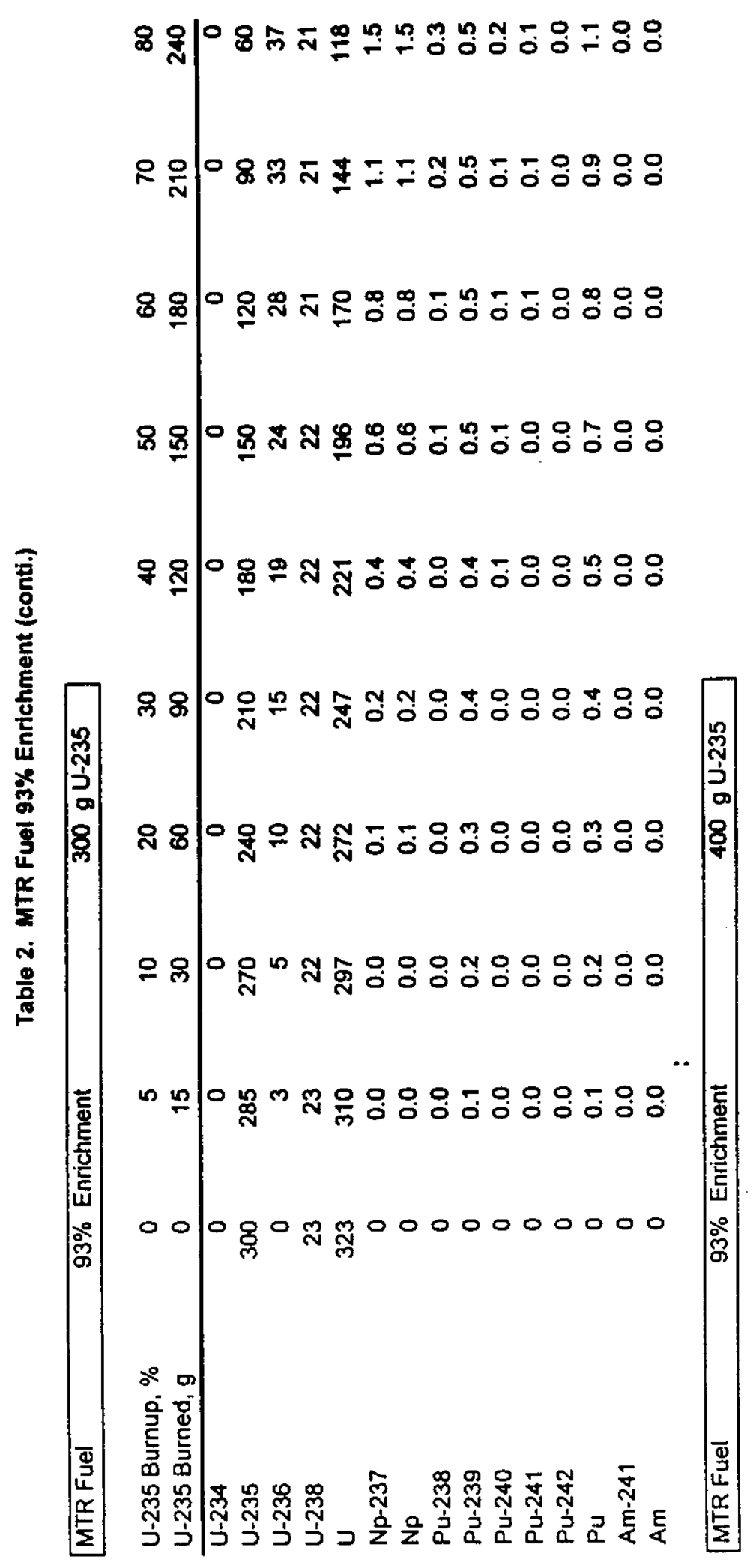

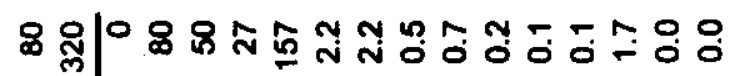

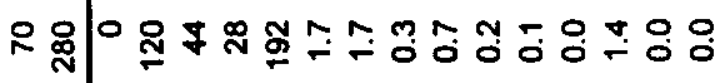

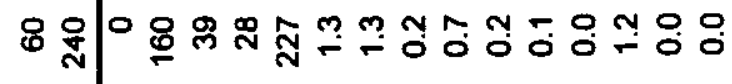

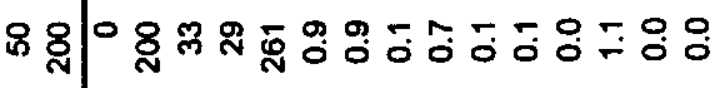

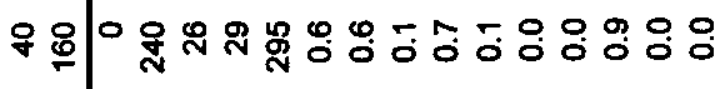

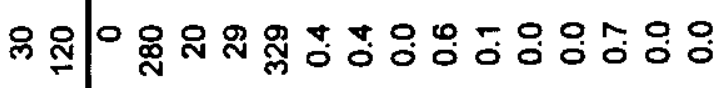

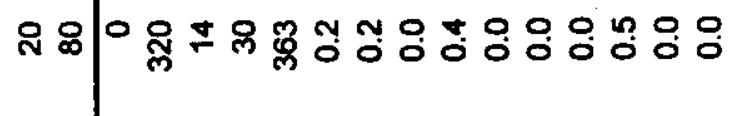

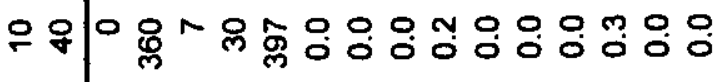

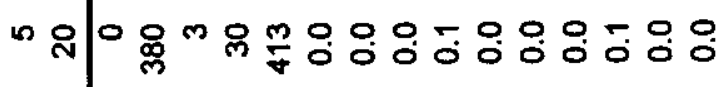

0000000000000000

의

完

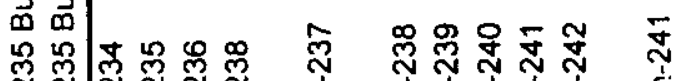

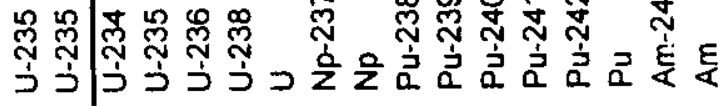




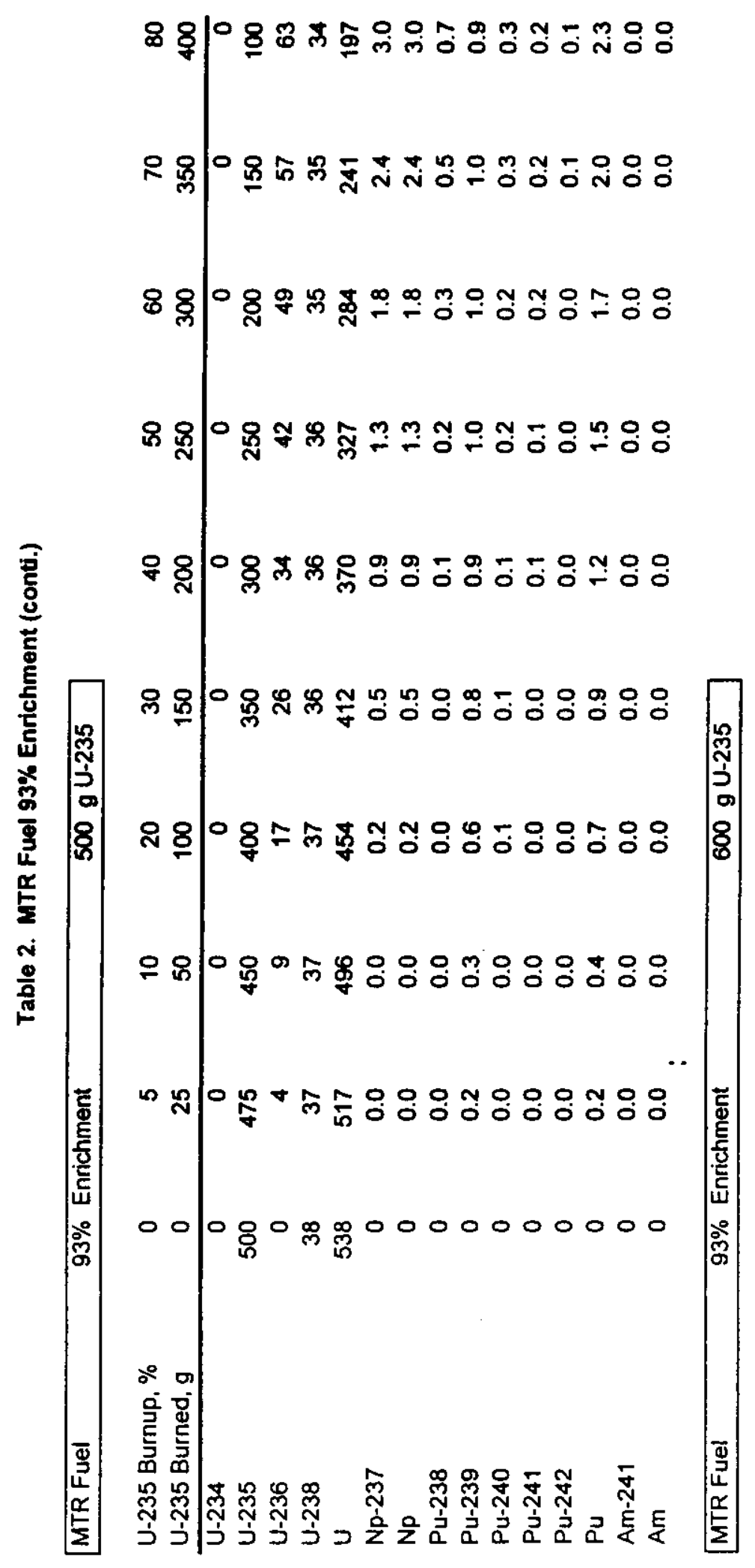

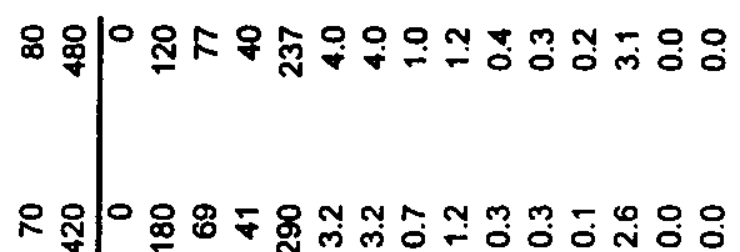

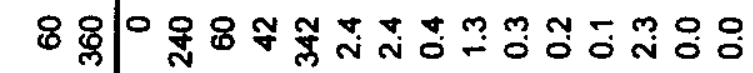

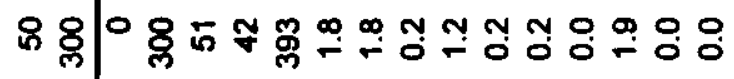

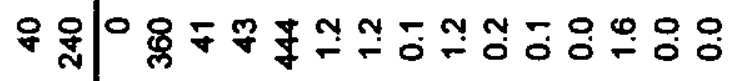

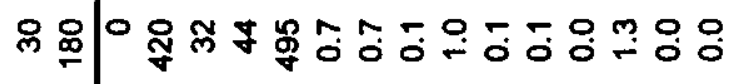

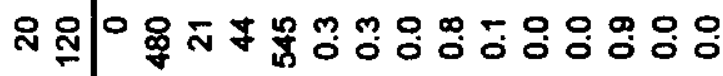

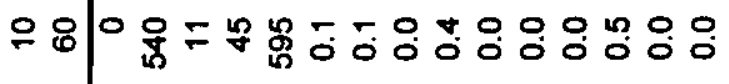

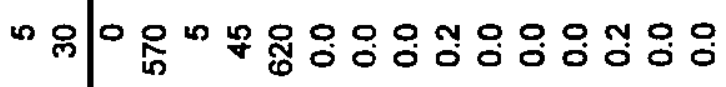

000808000000000

要

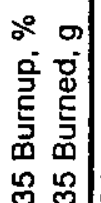

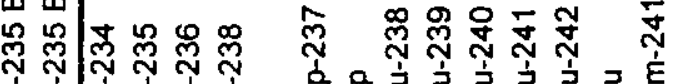

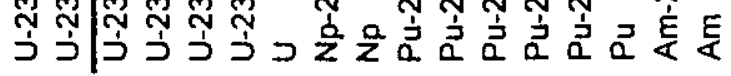




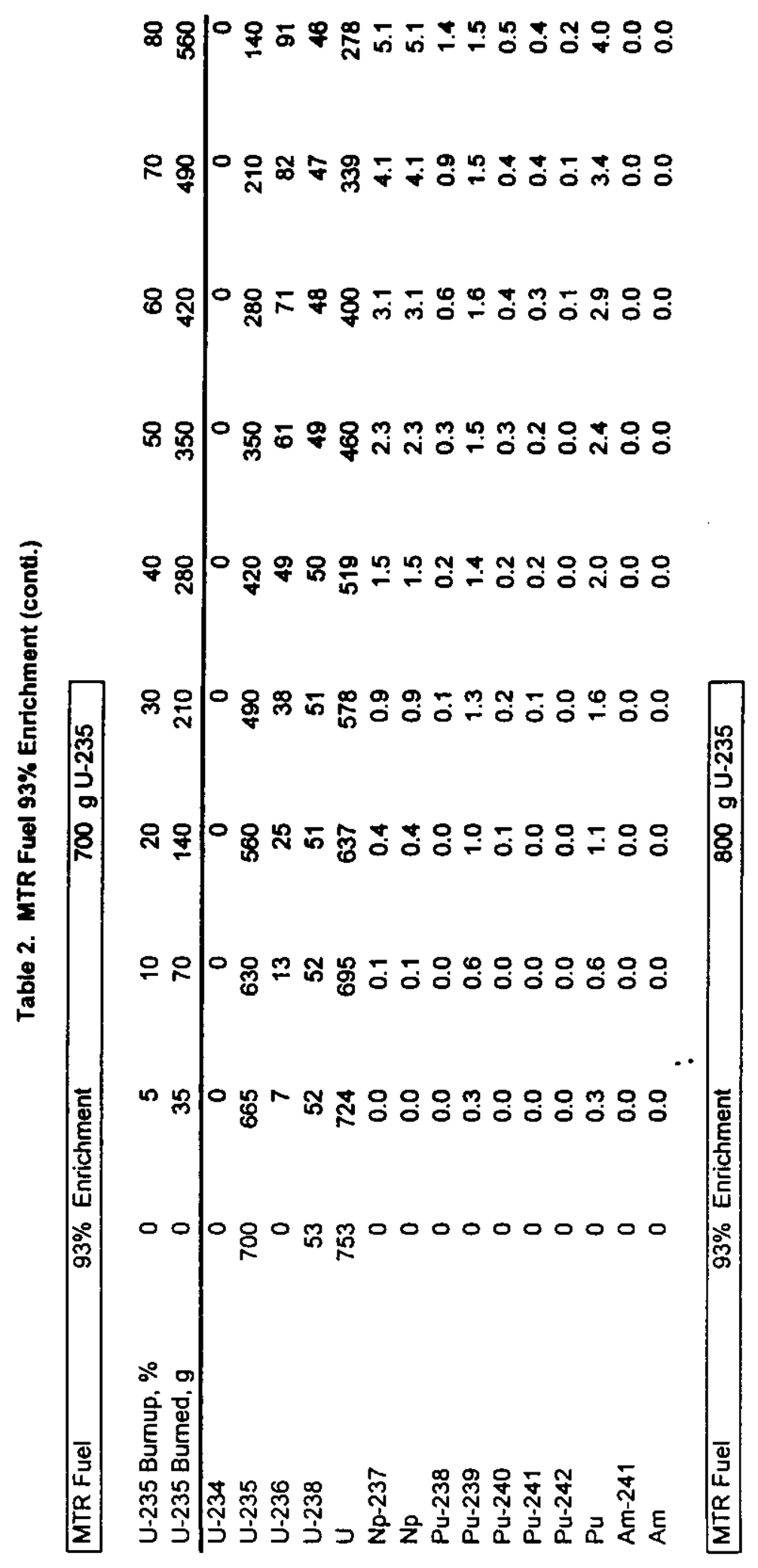

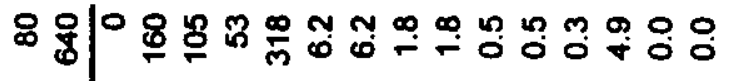

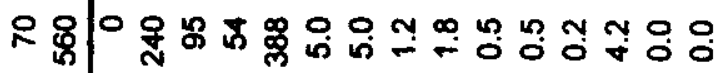

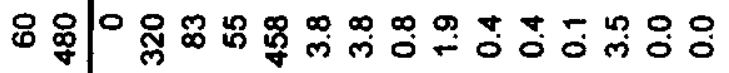

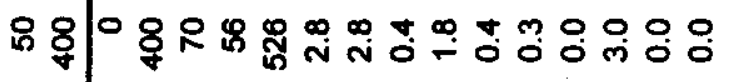

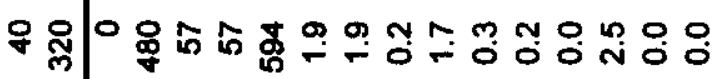

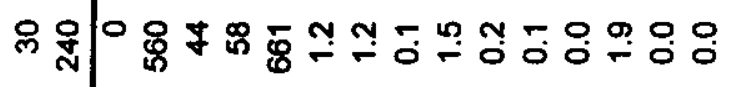

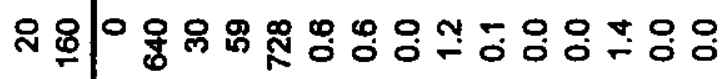

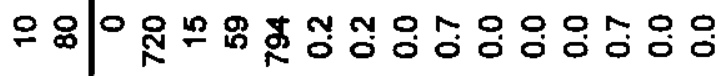

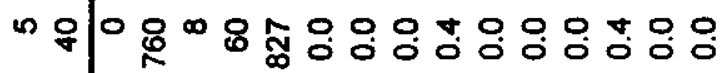

0008080000000000

$\therefore$ 잉

空

㠃 离

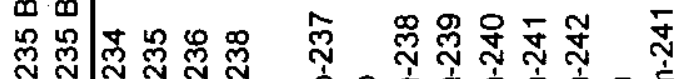

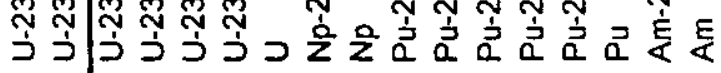




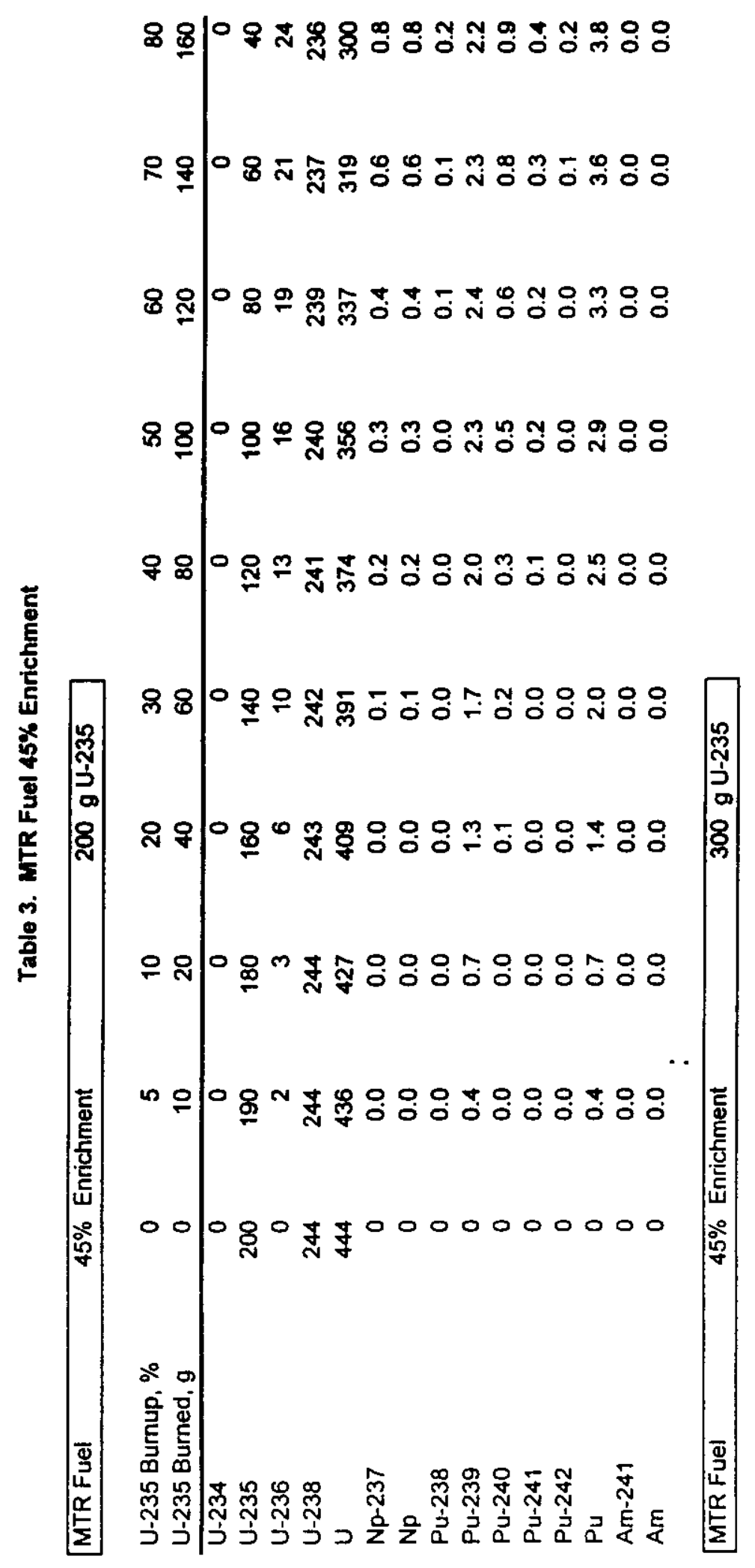

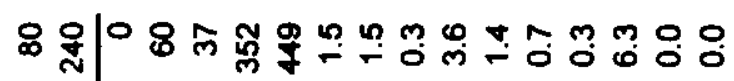

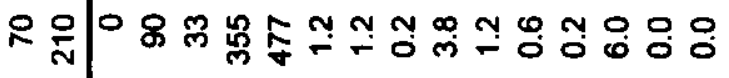

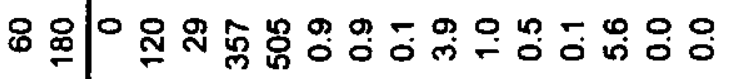

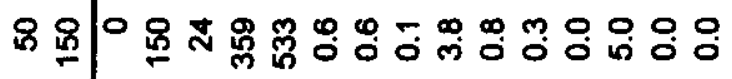

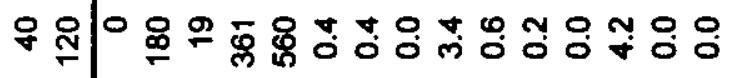

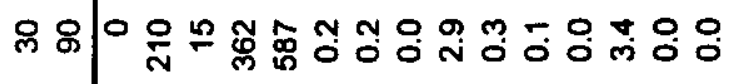

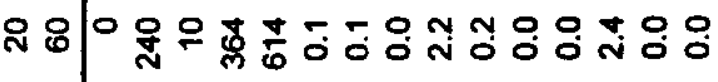

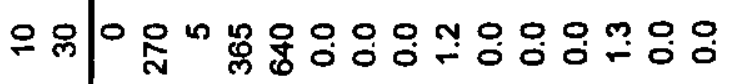

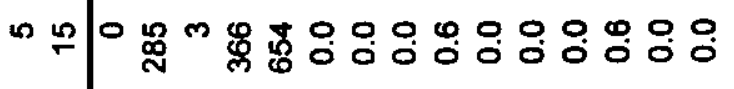

000000000000000

우

突

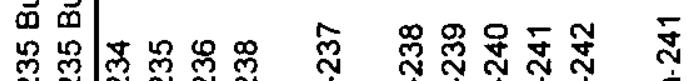

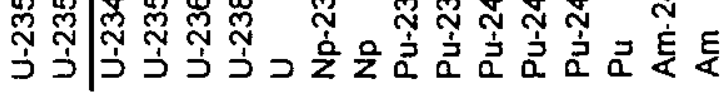




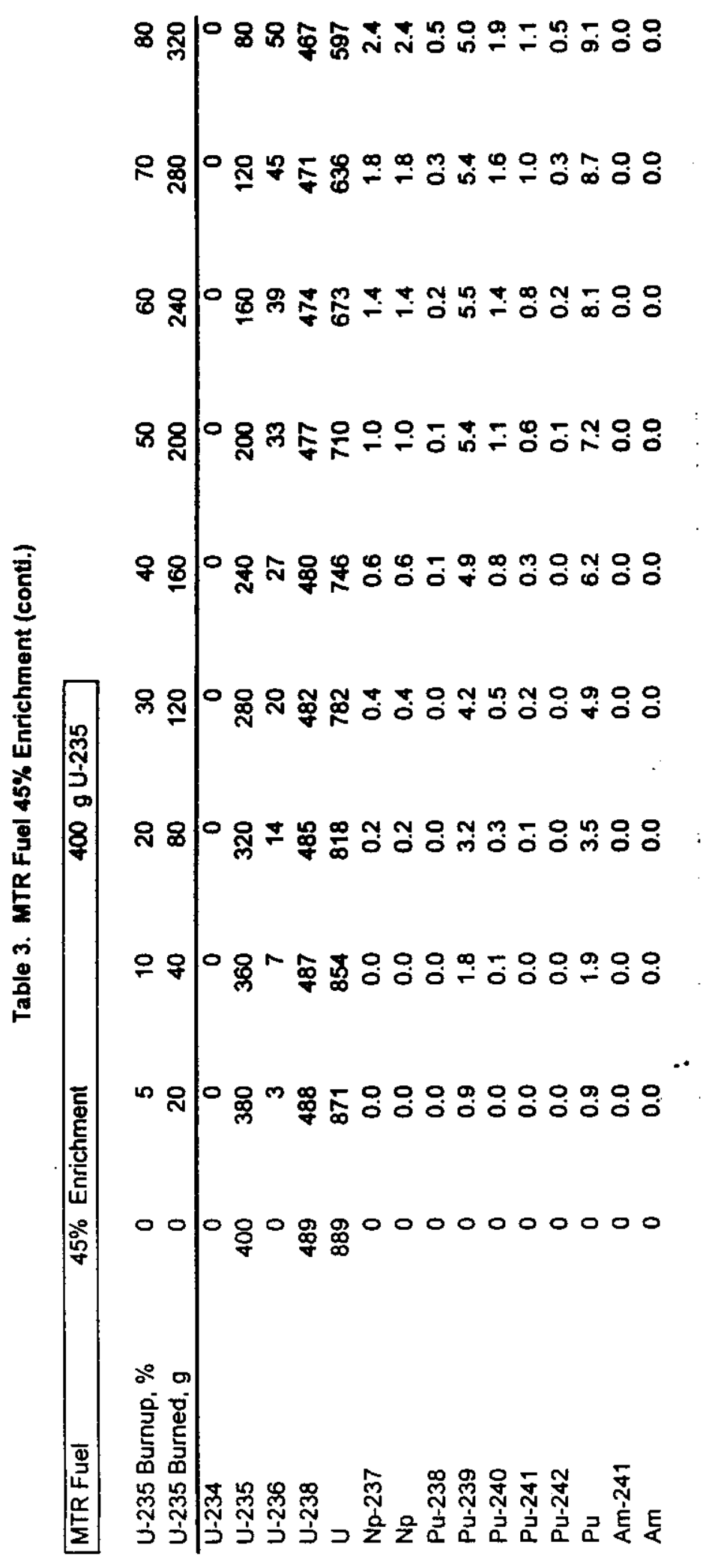




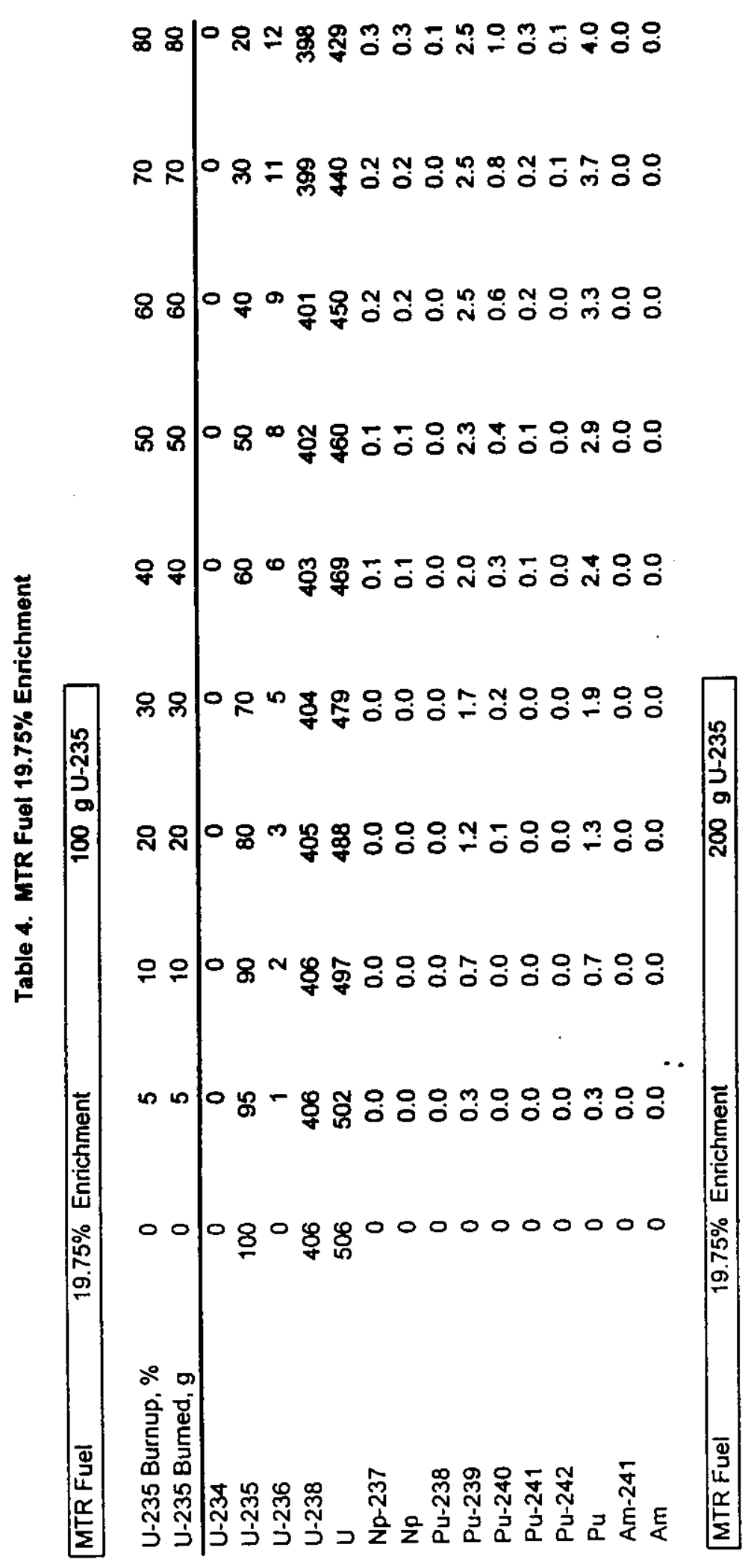

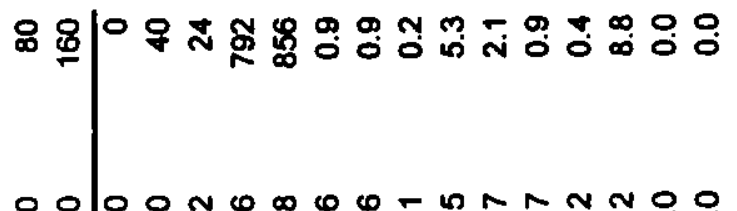

융요

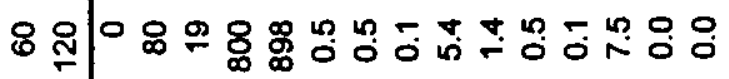

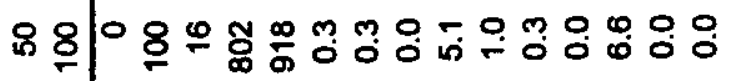

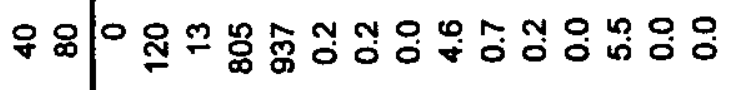

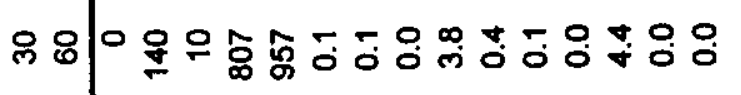

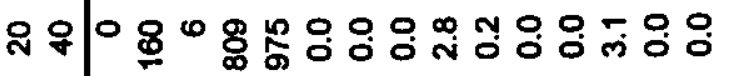

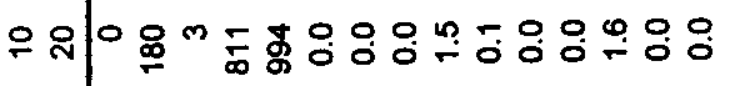

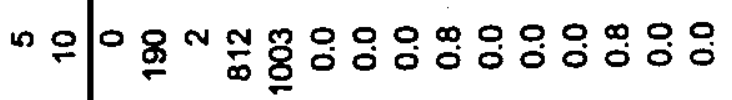

$0000^{\circ} \frac{m}{m} 0000000000$

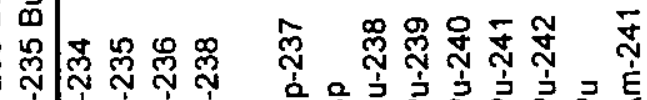
ذ่ 


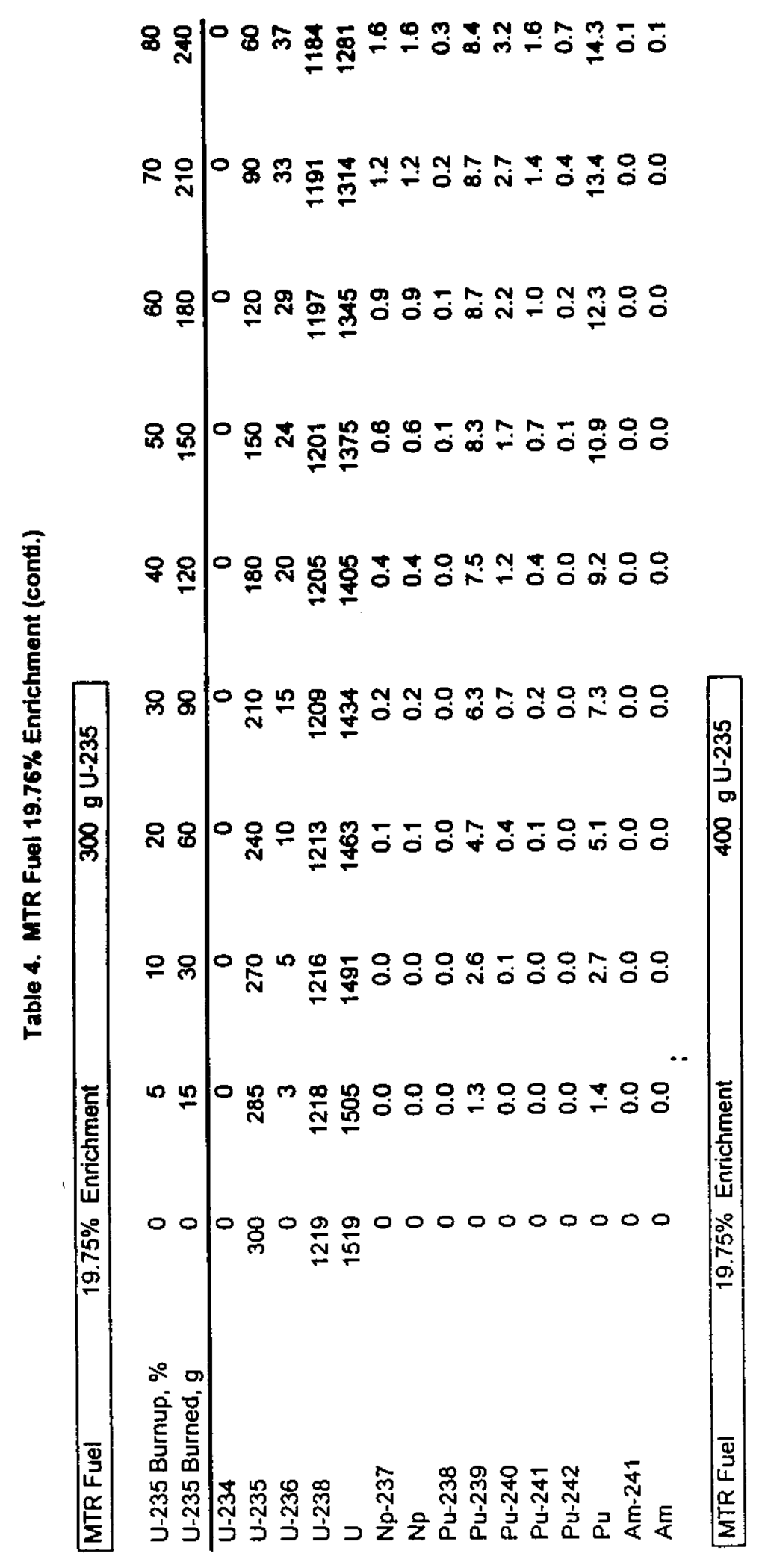

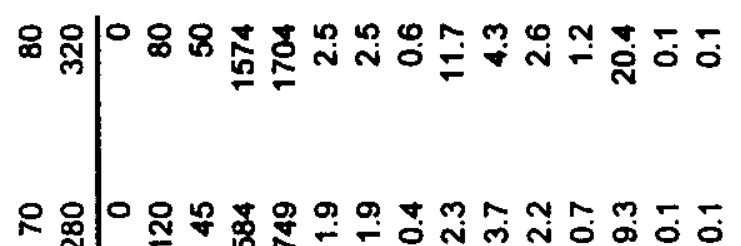

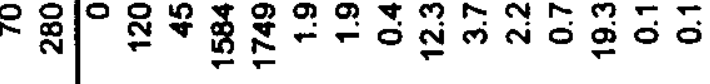

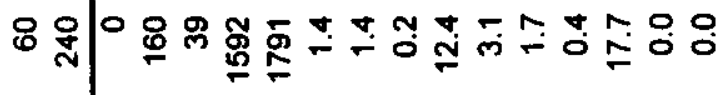

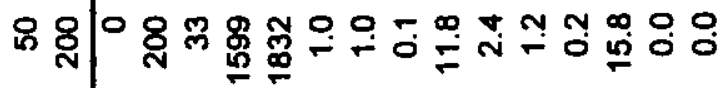

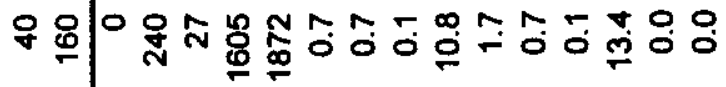

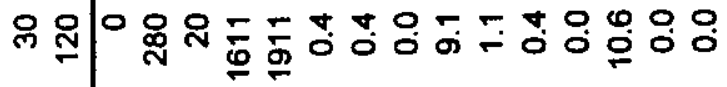

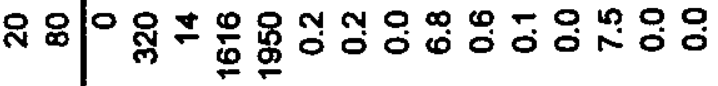

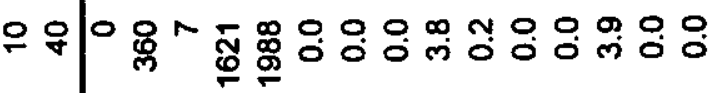

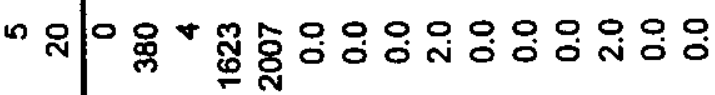

000 每楚

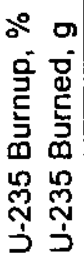

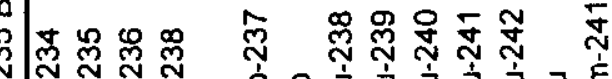

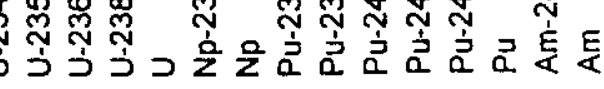




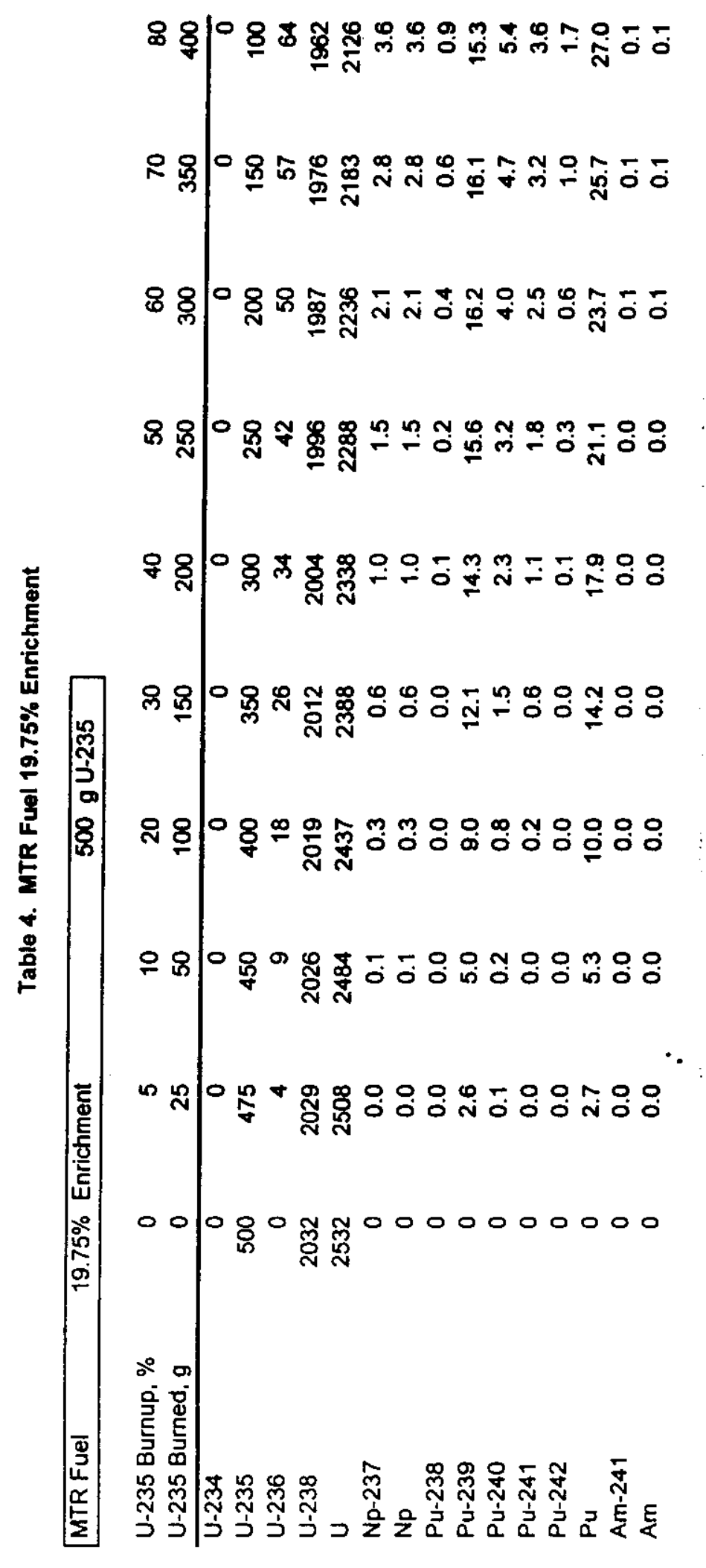




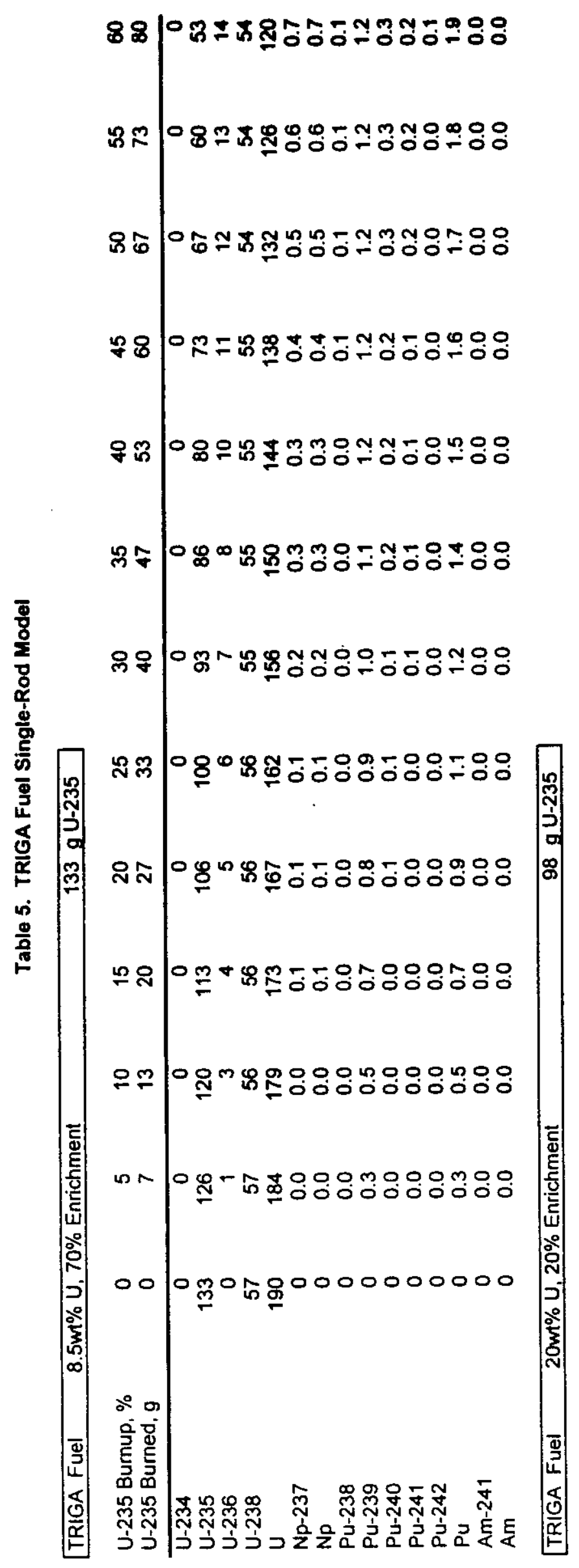

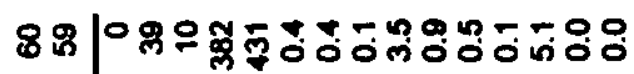

ถึฐ

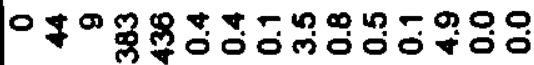

89

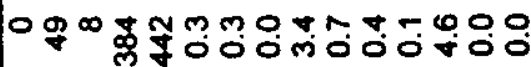

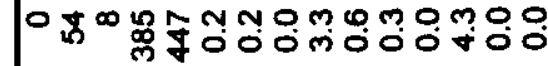

융ำ

四

N

สี

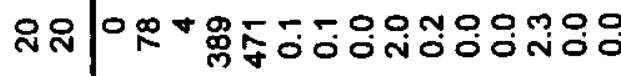

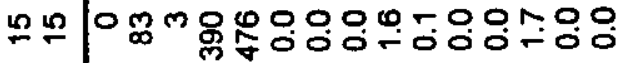

$\cdot$

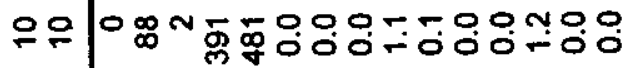

n

000 \% ్ㅐ용

尺̊

窝

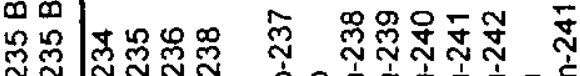

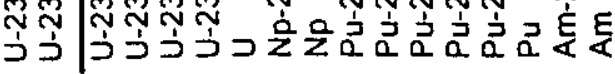



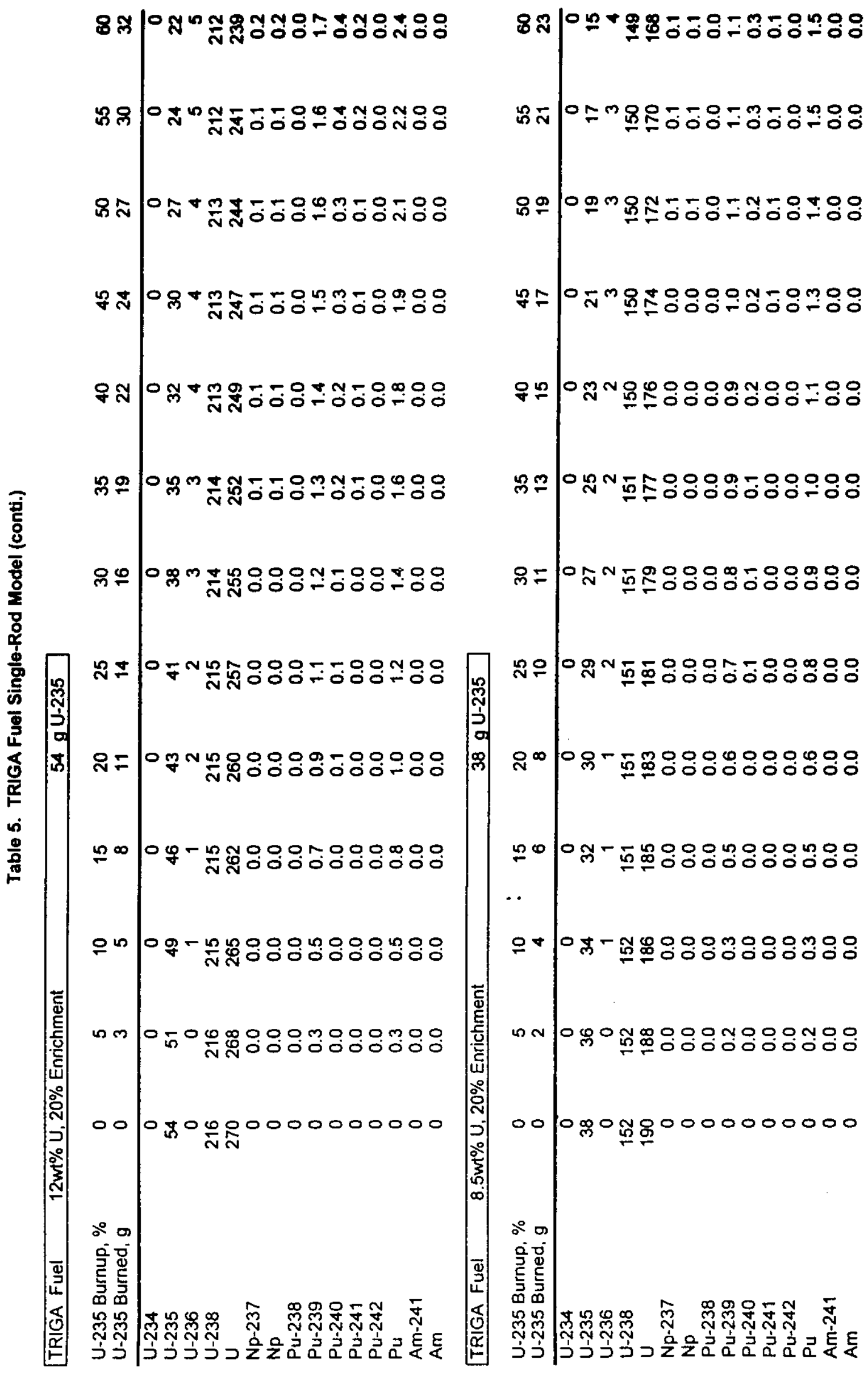


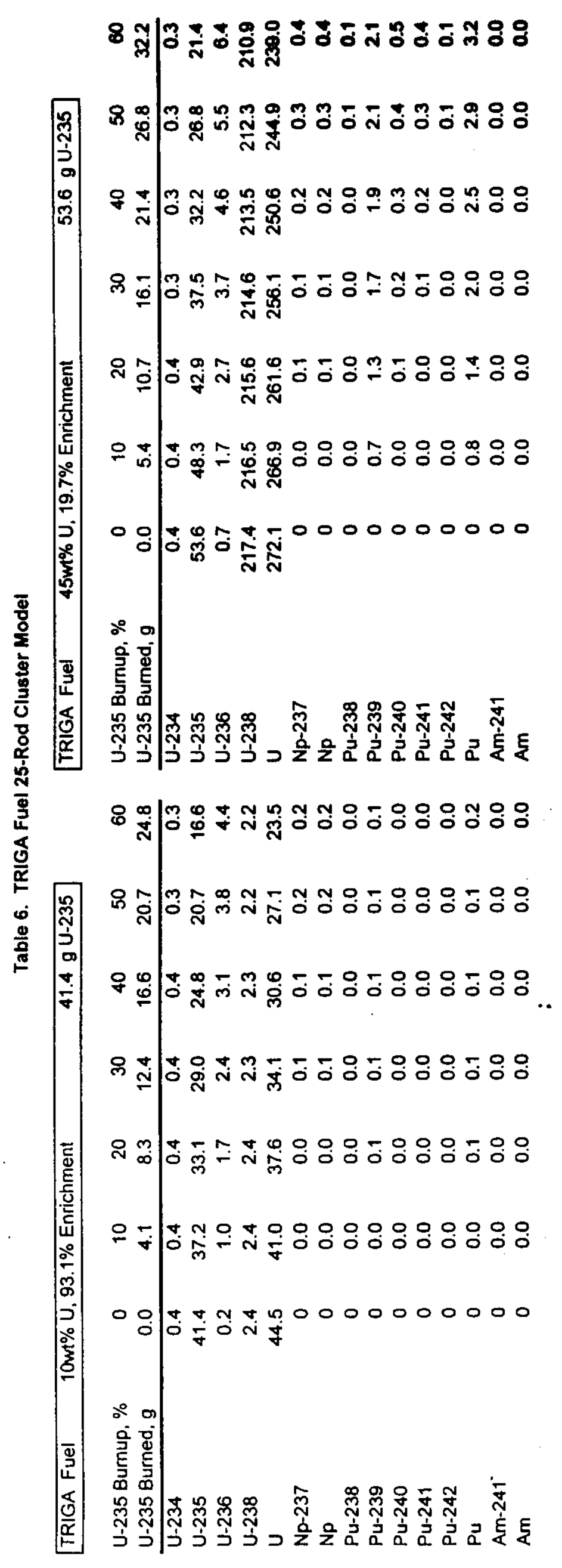




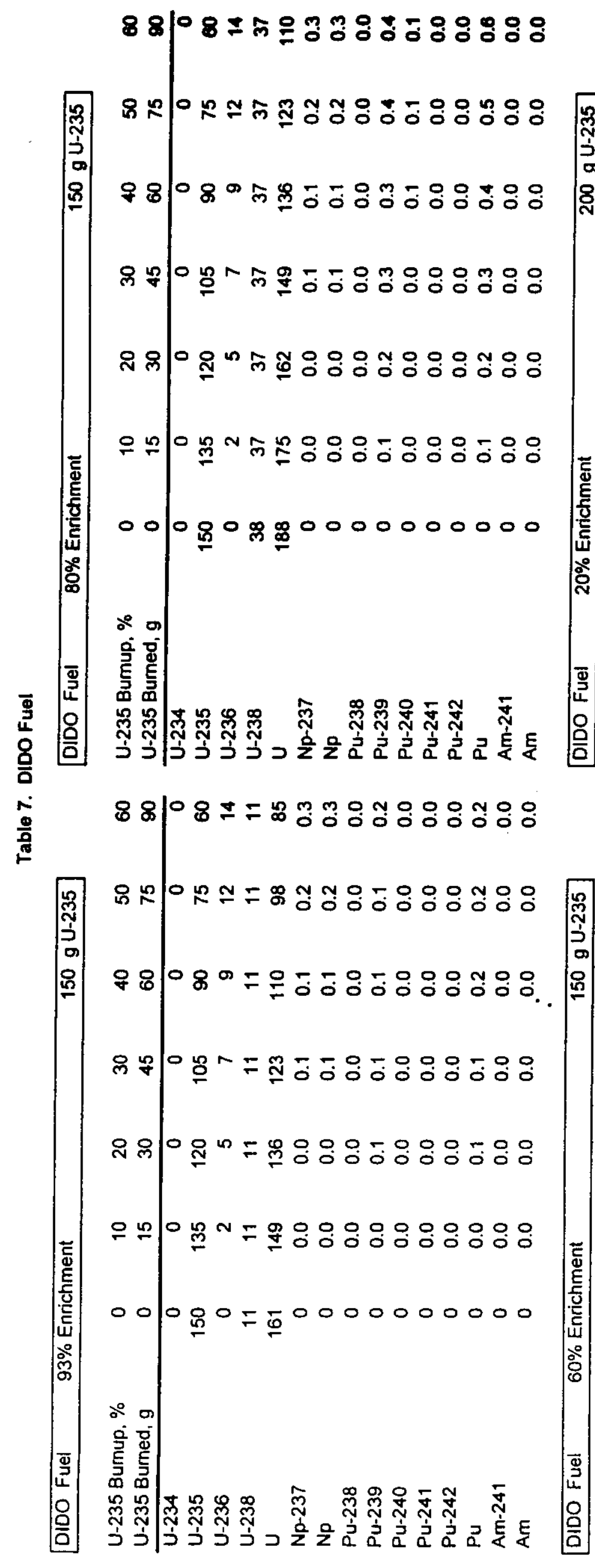

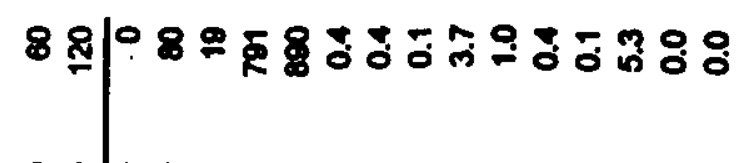

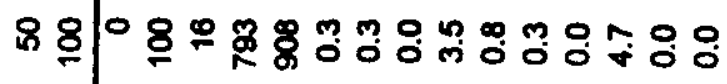

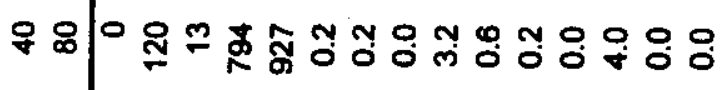

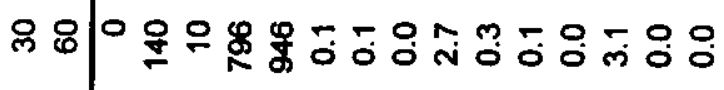

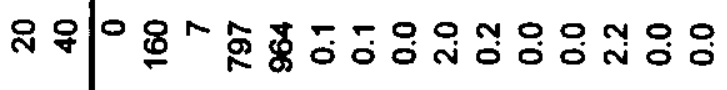

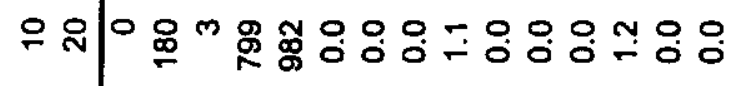

0008080000000000

$\therefore$ 이

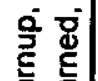

离

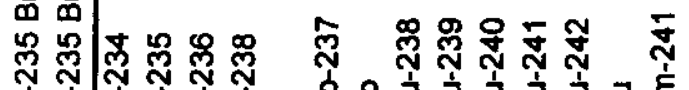

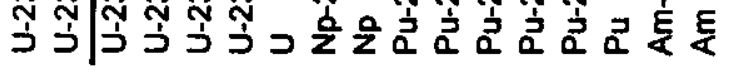

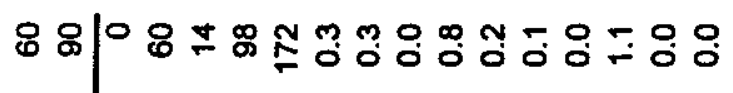

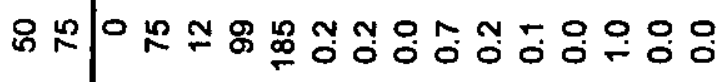

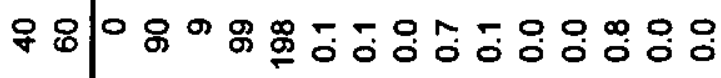

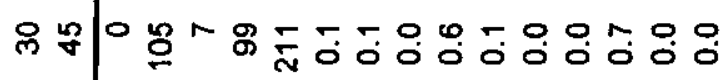

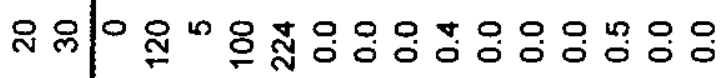

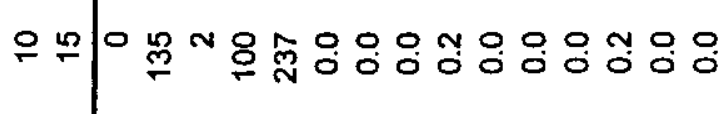

00000800000000000

$\therefore 0$

올

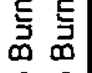

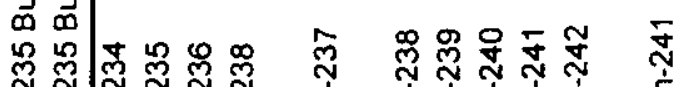

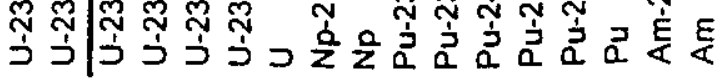




\section{APPENDIX A}

\section{MTR MODEL MASS INVENTORY SENSITIVITY}

This appendix examines the sensitivity of MTR-type fuel assemblies to the number of fuel plates in the assembly as well as the fuel element specifications for the fuel, clad and coolant. An examination of many MTR-type fuel assemblies shows that the ratio of the coolant channel thickness to the fuel meat thickness, times the number of fuel plates, is nearly a constant. This constant is also proportional to the $\mathrm{H} / \mathrm{U}-235$ atom ratio, which can be used to characterize the neutron spectrum in MTR-type fuel assemblies.

Figure Al shows the $\mathrm{H} / \mathrm{U}-235$ atom ratio as a function of the $\mathrm{U}-235$ mass. The upper curve are for 19 -plate $(0.51 \mathrm{~mm}$ fuel, $0.38 \mathrm{~mm}$ clad, $2.95 \mathrm{~mm}$ coolant) elements and the lower curve are for 23 -plate $(0.51 \mathrm{~mm}$ fuel, $0.38 \mathrm{~mm}$ clad, $2.19 \mathrm{~mm}$ coolant $)$ elements. Most all MTR-type fuel assemblies as a function of the fuel element specifications are within the range $( \pm 6 \%$ ) of the average $\mathrm{H} / \mathrm{U}-235$ ratio. 


\section{MTR Fuel Neutron Spectrum Characterization}

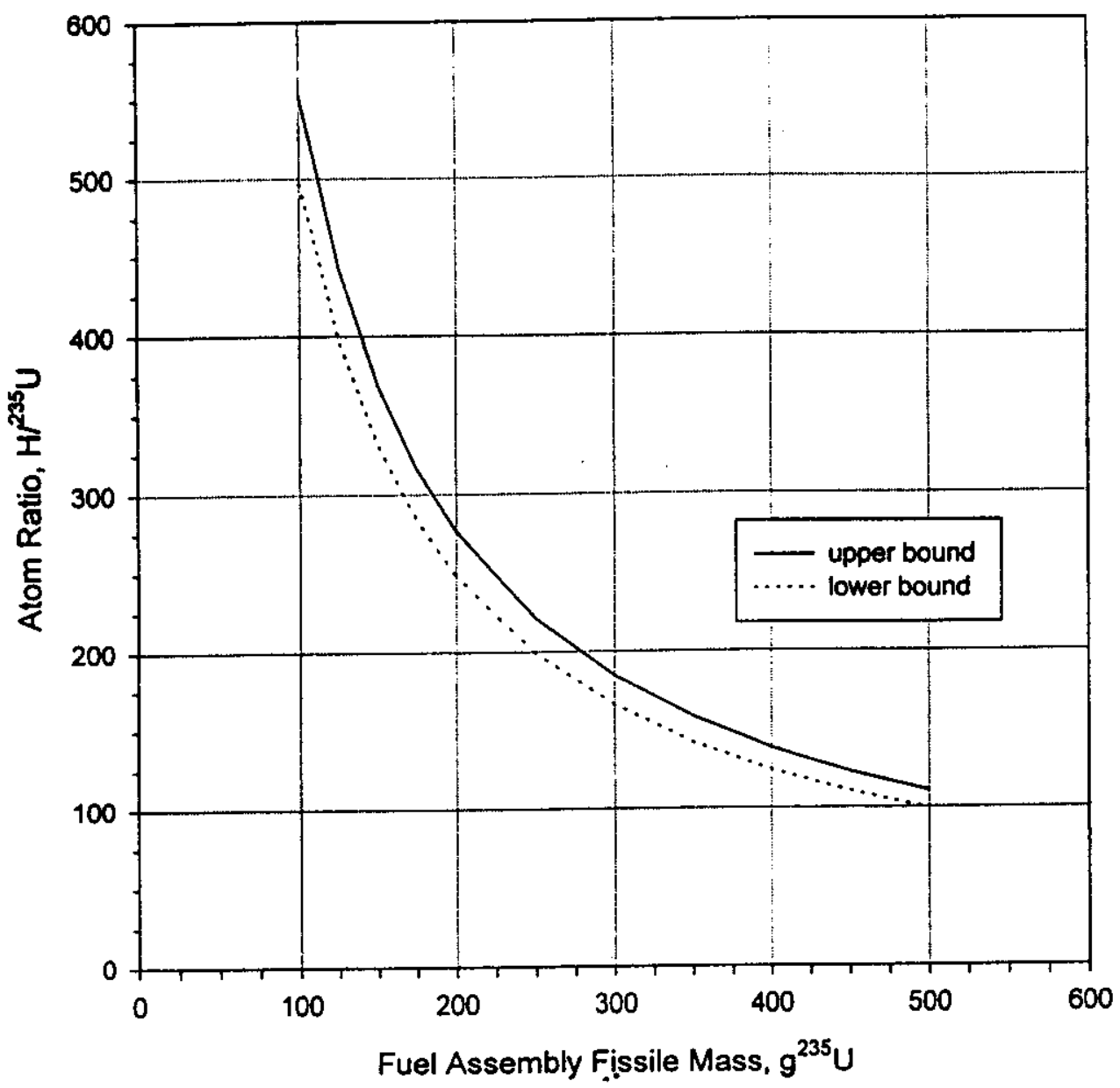

Figure A1. MTR Fuel Assembly Model Sensitivity

Tables A1-A3 show the mass inventory results for MTR fuel assembly types with $300 \mathrm{~g} \mathrm{U}-235$ and 93,45 and $19.75 \%$ U-235 enrichment. The difference between the upper and lower bound results indicate only small differences in the isotopic masses as a function of fuel element specification. 


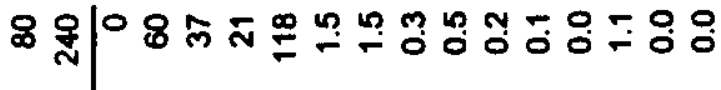

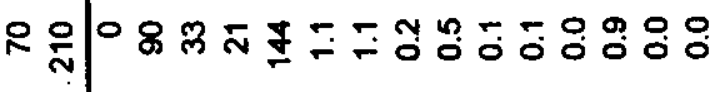

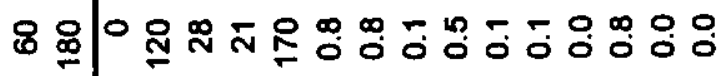

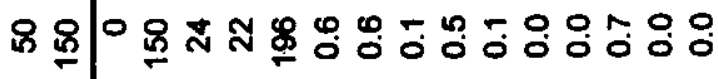

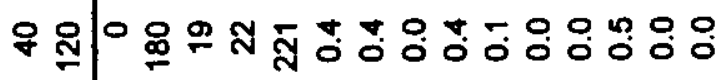

잉 \&

ก๊

का

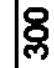

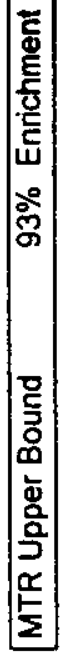

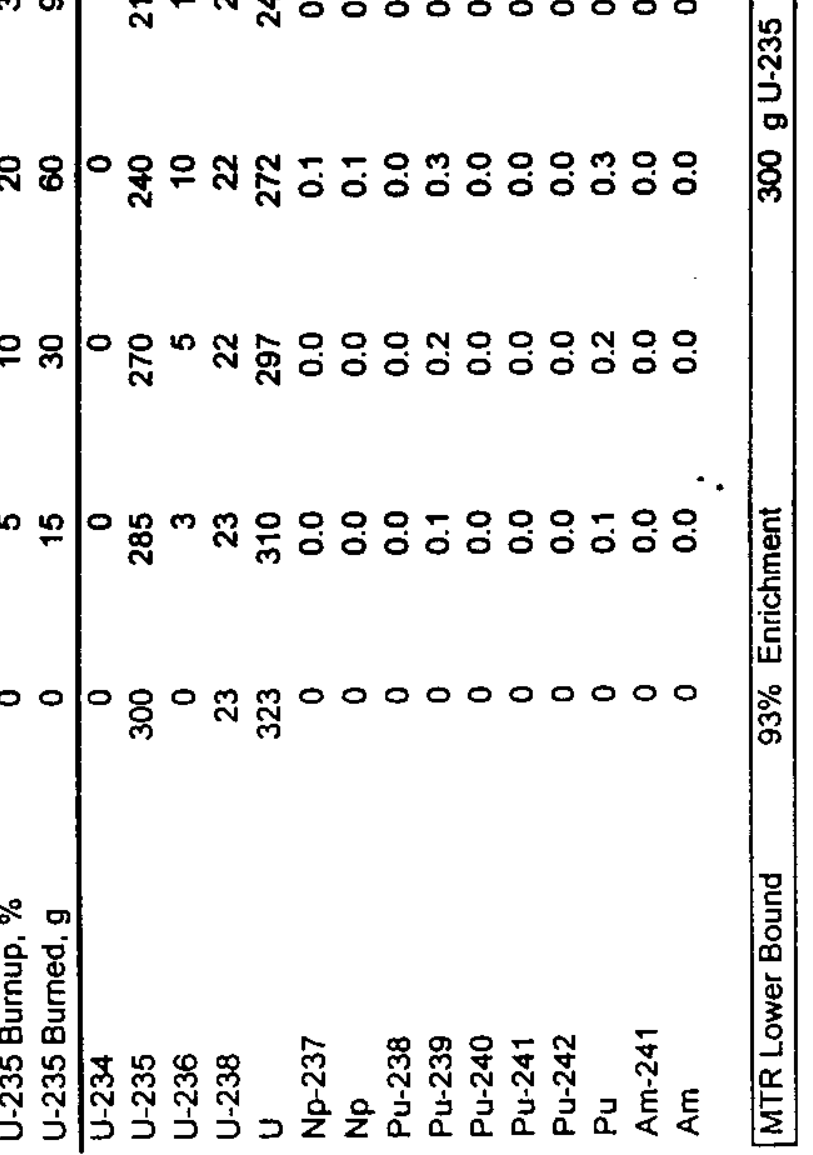

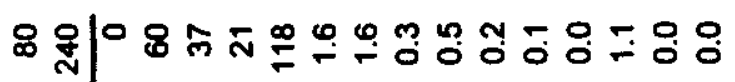

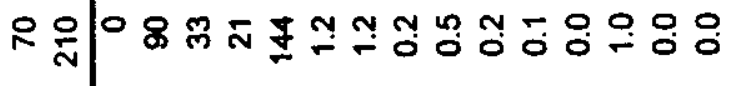

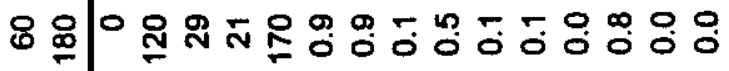

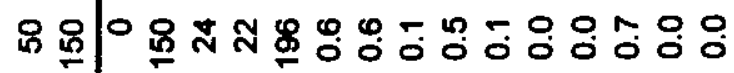

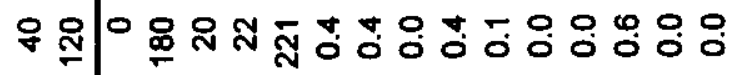

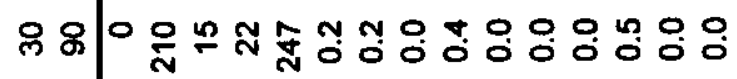

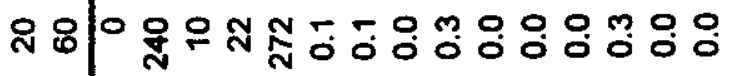

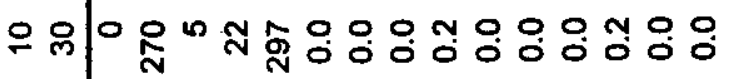

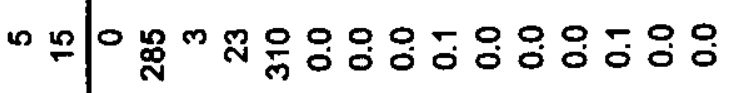

$00080 \mathrm{~m} / 0000000000$

의

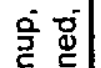

ह5

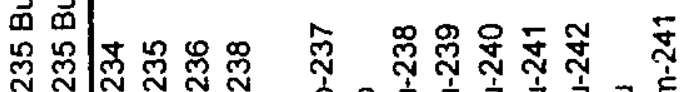

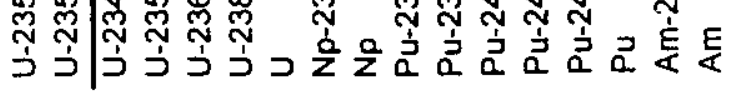




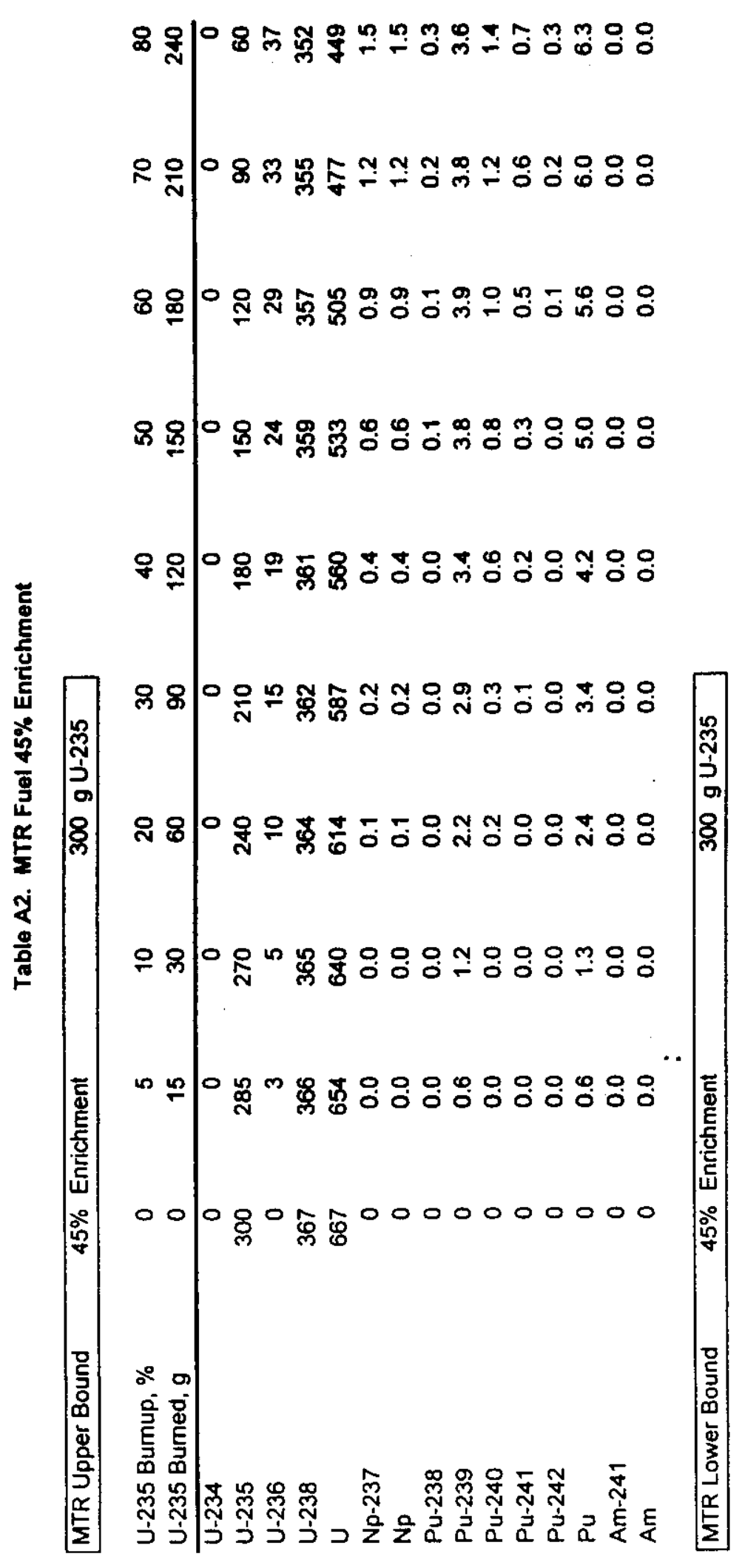

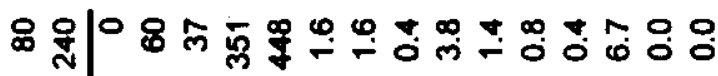

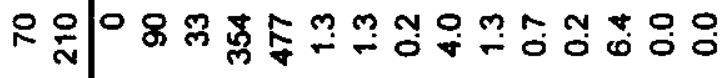

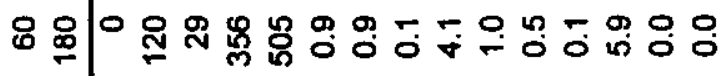

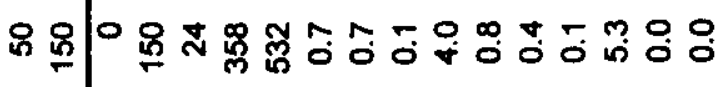

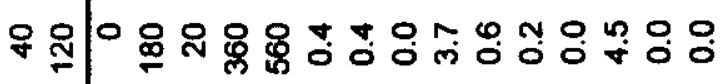

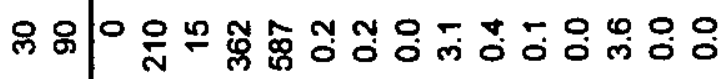

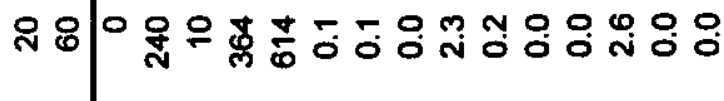

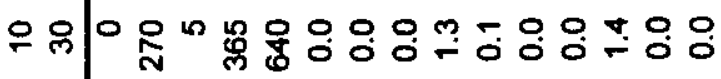

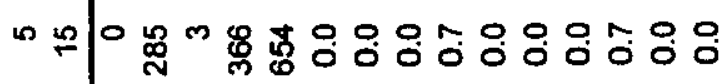

0000000000000000

เ

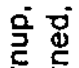

空

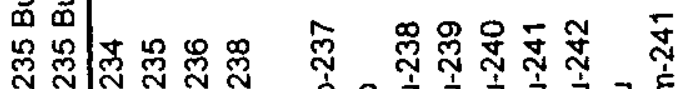

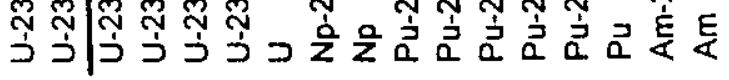




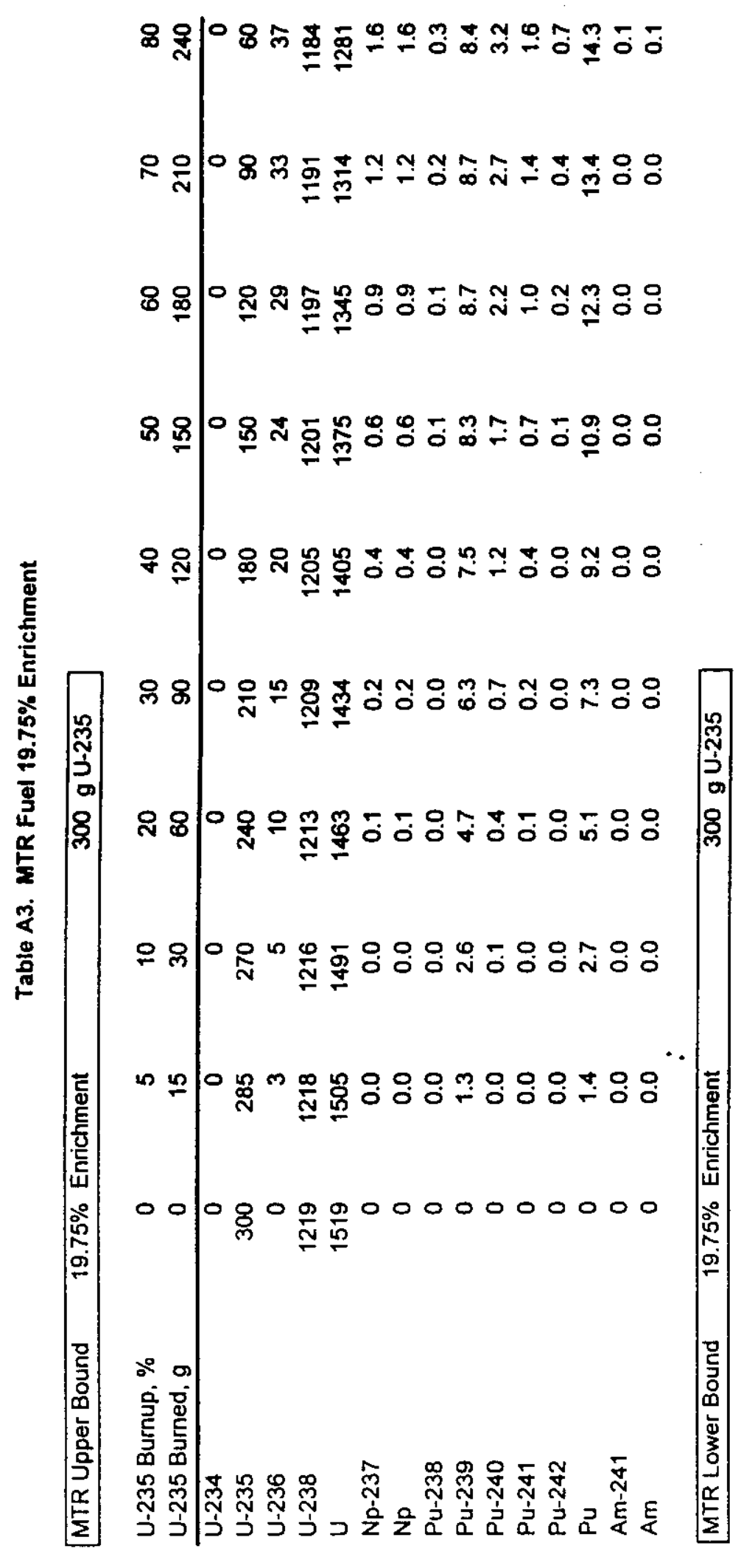

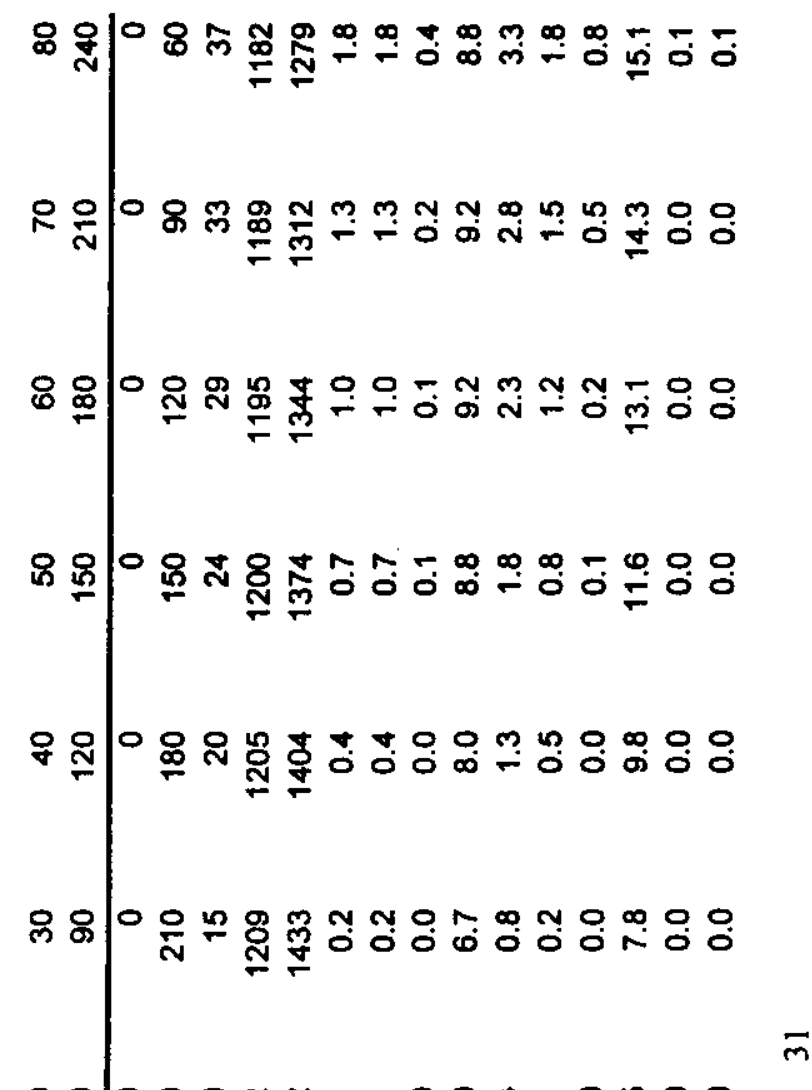

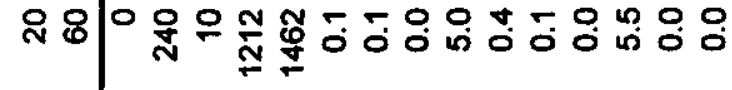

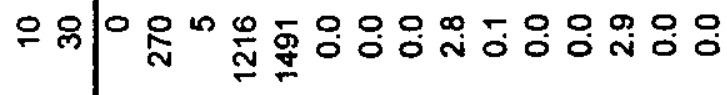

๓의 였

$00000 \frac{0}{2} \frac{0}{0} 0000000000$

일

产 空

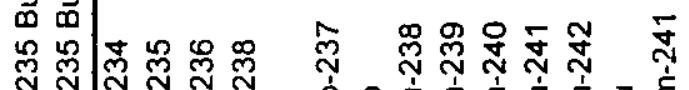

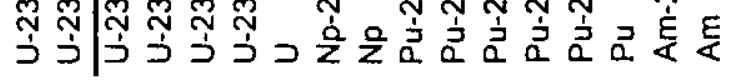




$$
\begin{gathered}
\because \vdots \\
\vdots \vdots \\
\vdots
\end{gathered}
$$




\section{APPENDIX B}

\section{U-234 AND U-236 MASS INVENTORY SENSITIVITY}

The initial fuel composition of some reactor fuels may contain specifications for U-234 and/or U-236 in addition to the usual specifications for U-235 and U-238. It is the purpose of this appendix to evaluate the effect that U-234 and U-236 have on the overall fuel-assembly mass inventory when these isotopes are or are not included in the initial fuel assembly composition.

A comparison of the fuel mass inventory for a HEU and a LEU fuel composition, with and without initial enrichments of U-234 and U-236, are shown in Table B1. Typical enrichments of U-234 and U-236 in research reactor fuels are less than 1\%; these specific data are for typical TRIGA fuel compositions.

The upper section of Table B1 shows the mass inventory for HEU and LEU fuels with initial enrichments of U-234 and U-236, and the lower section shows similar data for the same fuels but without initial U-234 and U-236 enrichment. The result of this comparison shows that to first-order, any initial mass of U-234 or U-236 can be simply added to the mass inventory for U-234, U-236 and total $U$ at any burnup level. The mass inventory for Np-237 and Pu-238 which, are also functions of the U-236 mass, are not substantially affected by an initial enrichment of U-236. 
ભొ

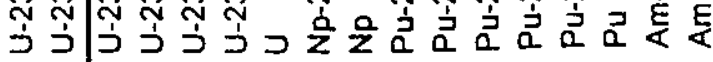




\section{APPENDIX C}

\section{MASS INVENTORY ESTIMATE: ORIGEN VS. WIMS}

In this paper, the spent fuel nuclear mass inventories are based upon material number densities calculated within the WIMS code using burnup dependent cross sections and fluxes to solve the material transmutation equations. Unit-cell models of MTR, TRIGA and DIDO fuel assemblies with typical fuel compositions used WIMS to generate actinide cross sections and number densities as a function of U-235 burnup.

Spot checks of the mass inventories for two TRIGA fuel compositions were also calculated using the isotope generation and depletion code, ORIGEN. The principal actinide cross sections input to ORIGEN were collapsed one-group, zero-burnup material cross sections calculated by WIMS.

The fuel material mass inventories predicted by ORIGEN and by WIMS for TRIGA fuel materials (133 $\mathrm{g}$ HEU and $38 \mathrm{~g} \mathrm{LEU}$ ) with $35 \% \mathrm{U}-235$ burnup are shown in Table $\mathrm{Cl}$. The uranium isotopes at the 1-gram level and the $\mathrm{Np}, \mathrm{Pu}$ and Am isotopes at the 0.1 -gram level are in reasonably good agreement. The slightly larger ${ }^{237} \mathrm{~Np}$ and ${ }^{239} \mathrm{Pu}$ and the slightly smaller ${ }^{238} \mathrm{U}$ inventories are due to the use of zero-burnup cross sections in estimating the $35 \% \mathrm{U}-235$ burnup inventories.

Table C1. Gram-Mass Inventory Estimates

\begin{tabular}{|l|c|c|c|c|}
\hline & \multicolumn{3}{|c|}{$8.5 \mathrm{wt} \%$ U, 70\% Enrichment } & \multicolumn{2}{c|}{$8.5 \mathrm{w} \%$ U, 20\% Enrichment } \\
\hline & \multicolumn{2}{|c|}{$133 \mathrm{~g} \mathrm{U}-235$} & \multicolumn{2}{c|}{$38 \mathrm{~g}$ U-235 } \\
\hline & ORIGEN & WIMS & ORIGEN & WIMS \\
\hline $\mathrm{U}-235$ Burnup, \% & 35 & 35 & 35 & 35 \\
\hline $\mathrm{U}-235$ Burned, $\mathrm{g}$ & 47 & 47 & 13 & 13 \\
\hline $\mathrm{U}-234$ & 0 & 0. & 0 & 0 \\
\hline $\mathrm{U}-235$ & 86 & 86 & 25 & 25 \\
\hline $\mathrm{U}-236$ & 8 & 8 & 2 & 2 \\
\hline $\mathrm{U}-238$ & 55 & 55 & 150 & 151 \\
\hline $\mathrm{U}$ & 150 & 150 & 177 & 177 \\
\hline $\mathrm{Np}-237$ & 0.4 & 0.3 & 0.0 & 0.0 \\
\hline $\mathrm{Np}$ & 0.4 & 0.3 & 0.0 & 0.0 \\
\hline Pu-238 & 0.0 & 0.0 & 0.0 & 0.0 \\
\hline Pu-239 & 1.3 & 1.1 & 0.9 & 0.9 \\
\hline Pu-240 & 0.2 & 0.2 & 0.1 & 0.1 \\
\hline Pu-241 & 0.1 & 0.1 & 0.0 & 0.0 \\
\hline Pu-242 & 0.0 & 0.0 & 0.0 & 0.0 \\
\hline Pu & 1.6 & 1.4 & 1.1 & 1.0 \\
\hline Am-241 & 0.0 & 0.0 & 0.0 & 0.0 \\
\hline Am & 0.0 & 0.0 & 0.0 & 0.0 \\
\hline
\end{tabular}


The mass inventories using the WIMS 35\%-burnup material cross sections as input to ORIGEN shows a change in the inventories in the direction of the WIMS results. In particular, the ${ }^{237} \mathrm{~Np}$ and ${ }^{239} \mathrm{Pu}$ inventories decrease and the ${ }^{238} \mathrm{U}$ inventory increases. With these cross sections, the ${ }^{237} \mathrm{~Np}$ and ${ }^{239} \mathrm{Pu}$ inventories are slightly underestimated compared to WIMS. The cross sections used in ORIGEN are not extremely sensitive to burnup, but they should be for a specific fuel material composition and not simply default-library cross sections. The difference between ORIGEN and WIMS inventories would be expected to increase as U-235 burnup increases.

Since the $\mathrm{Np}$ and $\mathrm{Pu}$ mass inventories calculated above are slightly overestimated using zero-burnup cross sections and slightly underestimated using 35\%-burnup cross sections, it is recommended that mid-cycle burnup cross sections be used in any ORIGEN mass inventory calculation. The mid-cycle cross sections would be expected to approximately cancel any over- or under-estimate and give inventory masses of $\mathrm{U}, \mathrm{Np}, \mathrm{Pu}$ and Am closer to the masses calculated with WIMS. 


\section{APPENDIX D}

\section{EXAMPLE CALCULATION: NUCLEAR MASS INVENTORY, PHOTON DOSE RATE, THERMAL DECAY HEAT AND FISSION PRODUCT DECAY RATE}

In this example, a $280 \mathrm{~g}^{235} \mathrm{U}$ MTR-type fuel assembly has been irradiated at an average fuel assembly power $(\bar{P})$ of $25 \mathrm{~kW}$ over an elapsed time $\left(t_{e}\right)$ of 3584 days. The irradiation history of this fuel assembly is such that it can not be described simply, using a constant power $(P)$ and a continuous irradiation time $\left(t_{i}\right)$. It is assumed, however, that

$$
\bar{P} \cdot t_{e}=89.6 M W d=\sum\left(P \cdot t_{i}\right)
$$

where the sum of $\left(P \cdot t_{i}\right)$ traces the fuel assembly irradiation history over all irradiation segments when the fuel assembly power was constant and the irradiation time was continuous. The elapsed time is the calendar time from the first through the last irradiation segment. Assuming $1.25 \mathrm{~g}^{235} \mathrm{U}$ burned per $\mathrm{MWd}$, this fuel assembly has $112-$ $\mathrm{g}^{235} \mathrm{U}$ burned and $40 \%{ }^{235} \mathrm{U}$ burnup. The fission product decay time $\left(t_{d}\right)$ or cooling time for this fuel assembly is assumed to be 3 years.

\section{Nuclear Mass Inventory}

If the fuel assembly enrichment is $93 \%$, then $300 \mathrm{~g}^{235} \mathrm{U}, 40 \%{ }^{235} \mathrm{U}$ burnup data of Table 2 can be prorated to $280 \mathrm{~g}^{235} \mathrm{U}$. For enrichments of 45 or $19.75 \%$, similar prorated data from Table 3 or 4 , respectively, should be used. Table Dl summarizes the spent fuel mass inventory of $280 \mathrm{~g}^{235} \mathrm{U}$ fuel assemblies, which have $40 \%{ }^{235} \mathrm{U}$ burnup.

Table D1. Mass Inventory of Spent HEU, MEU and LEU Fuel Assemblies

\begin{tabular}{|l|c|c|c|}
\hline Isotope & HEU-93\% & MEU-45\% & LEU-19.75\% \\
\hline$U-234$ & 0 & 0 & 0 \\
\hline$U-235$ & 168 & 168 & 168 \\
\hline$U-236$ & 18 & 18 & 19 \\
\hline$U-238$ & 21 & 337 & 1125 \\
\hline$U$ & 206 & 523 & 1311 \\
\hline $\mathrm{Np}-237$ & 0.4 & 0.4 & 0.4 \\
\hline $\mathrm{Np}$ & 0.4 & 0.4 & 0.4 \\
\hline $\mathrm{Pu}-238$ & 0.0 & 0.0 & 0.0 \\
\hline $\mathrm{Pu}-239$ & 0.4 & 3.2 & 7.0 \\
\hline $\mathrm{Pu}-240$ & 0.1 & 0.6 & 1.1 \\
\hline $\mathrm{Pu}-241$ & 0.0 & 0.2 & 0.4 \\
\hline $\mathrm{Pu}-242$ & 0.0 & 0.0 & 0.0 \\
\hline $\mathrm{Pu}$ & 0.5 & 3.9 & 8.6 \\
\hline $\mathrm{Am}-241$ & 0.0 & 0.0 & 0.0 \\
\hline $\mathrm{Am}$ & 0.0 & 0.0 & 0.0 \\
\hline
\end{tabular}


These $280 \mathrm{~g}^{235} \mathrm{U}$ spent fuel inventory masses could also have been estimated using linear interpolation of the 200 and $300 \mathrm{~g}^{235} \mathrm{U}, 40 \%{ }^{235} \mathrm{U}$ burmup data tabulated in Tables 2,3 and 4. Note, inventory masses for non-tabulated fuel assembly burnup should also use linear interpolation of tabulated data (e.g. $45 \%{ }^{235} \mathrm{U}$ burnup, interpolate between 40 and $50 \%$ tabulated data).

\section{Photon Dose Rate}

The photon dose rate of this fuel assembly is calculated from data presented in Table 8. The assembly power density is $0.089 \mathrm{MW} / \mathrm{kg}^{235} \mathrm{U}\left(25 \mathrm{~kW} / 280 \mathrm{~g}^{235} \mathrm{U}\right)$, the ${ }^{235} \mathrm{U}$ burnup is $40 \%$, and the decay time is 3 years. With these data, Table 8 estimates that the photon dose rate is $1.02 \mathrm{rem} / \mathrm{h}$ per $\mathrm{g}^{235} \mathrm{U}$ burned. With $112 \mathrm{~g}^{235} \mathrm{U}$ burned, the dose rate is $114 \mathrm{rem} / \mathrm{h}$ at 1 meter from the fuel assembly.

For fuel with $40 \%$ burnup and with $112 \mathrm{~g}^{235} \mathrm{U}$ burned, Fig. 1 estimates that this fuel assembly will be self-protecting (dose rate greater than $100 \mathrm{rem} / \mathrm{h}$ ) for about 4 years.

The photon dose rate for non-tabulated assembly power densities, ${ }^{235} U$ burnup and/or decay times can be estimated using linear interpolation of the data in Table 8. Linear interpolation to determine the photon dose rate would be necessary, for example, for a fuel assembly with the following parameters: 3.5 year decay time, $50 \%{ }^{235} \mathrm{U}$ burnup and $0.134 \mathrm{MW} / \mathrm{kg}^{235} \mathrm{U}$ assembly power density. A simple table, which interpolates each parameter separately, is a useful aid. Table D2 is constructed to determine the photon dose rate for these non-tabulated fuel assembly parameters.

Table D2. Fuel Assembly Parameter Linear Interpolation

\begin{tabular}{|c|c|c|c|}
\hline $\begin{array}{c}\text { Decay } \\
\text { Time, } y\end{array}$ & $\begin{array}{c}\text { Burnup. } \\
\%{ }^{235} \mathrm{U}\end{array}$ & $\begin{array}{c}\text { Assembly Power } \\
\text { Density, MW/kg }\end{array}$ & $\begin{array}{c}\text { Photon Dose Rate, } \\
\text { rem/h per } \mathrm{g}^{235} \mathrm{U} \text { burned }\end{array}$ \\
\hline 3 & 50 & 0.179 & 1.31 \\
\hline 3 & 50 & 0.089 & 1.07 \\
\hline 3 & 50 & 0.134 & 1.19 \\
\hline 4 & 50 & 0.179 & 1.10 \\
\hline 4 & 50 & 0.089 & 0.931 \\
\hline 4 & 50 & 0.134 & 1.0155 \\
\hline 3.5 & 50 & 0.134 & 1.10 \\
\hline
\end{tabular}

The bottom line, estimated photon dose rate is $1.10 \mathrm{rem} / \mathrm{h}$ per $\mathrm{g}^{235} \mathrm{U}$ burned. 


\section{Thermal Decay Heat}

\section{ORIGEN Calculation}

The thermal decay heat calculated with the ORIGEN code for this example is about 4.2 Watts.

\section{Integrated Emission Rate Equation}

The thermal decay heat of this fuel assembly using the conservative heat load equation based upon Eq. - 1

$$
H \cong 6.85 \cdot 10^{-3} \cdot \bar{P} \cdot\left(t_{d}-0.2-\left(t_{e}+t_{d}\right)^{-0.2}\right) \text { Watts }
$$

is about $10.6 \mathrm{~W}$. This result is based upon an average fuel assembly power $(\bar{P})$ of 25,000 Watts, a cooling or decay time $\left(t_{d}\right)$ of 1095 days $(3 \mathrm{y})$ and an elapsed time $\left(t_{e}\right)$ of 3584 days. The fission product decay rate of this fuel assembly, based upon Eq. $-1 \mathrm{a}$

$$
A \cong 1.37 \cdot \bar{P} \cdot\left(t_{d}^{-0.2}-\left(t_{i}+t_{d}\right)^{-0.2}\right) \text { Curies }
$$

is about $2130 \mathrm{C}$.

\section{El-Wakil Equation}

The thermal decay heat with these same data and the heat load equation based upon Eq. -2

$$
H \cong 4.95 \cdot 10^{-3} \cdot \bar{P} \cdot t_{d}{ }^{-0.06} \cdot\left(t_{d}{ }^{-0.2}-\left(t_{e}+t_{d}\right)^{-0.2}\right) \text { Watts }
$$

is about $5.1 \mathrm{~W}$. Using Fig. 3, the ratio of the decay rate-to-heat load is about 240 and the fission product radioactivity is about $1224 \mathrm{C}$ or $1346 \mathrm{C}$ including an additional $10 \%$.

\section{Untermyer and Weills Equation}

Similarly, using the heat load equation based upon Eq. -3 with a decay time of $9.46 \cdot 10^{7}$ seconds ( $1095 \mathrm{~d}$ ) and an elapsed time of $3.10 \cdot 10^{8}$ seconds ( $3584 \mathrm{~d}$ )

$$
\begin{aligned}
& H \cong 0.1 \cdot \bar{P} \cdot\left[\left(t_{d}+10\right)^{-0.2}-\left(t_{e}+t_{d}+10\right)^{-0.2}\right] \\
&-0.087 \cdot \bar{P} \cdot\left[\left(t_{d}+2 \cdot 10^{7}\right)^{-0.2}-\left(t_{e}+t_{d}+2 \cdot 10^{7}\right)^{-0.2}\right] \text { Watts }
\end{aligned}
$$

is about $3.8 \mathrm{~W}$. From Fig. 4, the ratio of the decay rate-to-heat load is about 325 and the fission product radioactivity is about $1235 \mathrm{C}$ or $1359 \mathrm{C}$ including an additional $10 \%$. 
